PNL-7126

UC-245

\title{
Low-Temperature Conversion of High-Moisture Biomass \\ Continuous Reactor System Results
}
D. C. Elliott
E. G. Baker
L. J. Sealock, Jr.
G. G. Neuenschwander
R. S. Butner

October 1989

Prepared for

the Biofuels and Municipal Waste

Technology Division

U.S. Department of Energy

under Contract DE-AC06-76RLO 1830

Pacific Northwest Laboratory

Richland, Washington 99352 


\section{DISCLAIMER}

This program was prepared as an account of work sponsored by an agency of the United States Government. Neither the United States Government nor any agency thereof, nor Battelle Memorial Institute, nor any or their employees, makes any warranty, expressed or implied, or assumes any legal liability or responsibility for the accuracy, completeness, or usefulness of any information, apparatus, product, or process disclosed, or represents that its use would not infringe privately owned rights. Reference herein to any specific commercial product, process, or service by trade name, trademark, manufacturer, or otherwise, does not necessarily constitute or imply its endorsement, recommendation, or favoring by the United States Government of any agency thereof, or BattelleMemorial Institute. The views and opinions of authors expressed herein do not necessarily state or reflect those of the United States Government or any agency thereof.

\section{PACIFIC NORTHWEST LABORATORY operated by \\ BATTELLE MEMORIAL INSTITUTE for the \\ UNITED STATES DEPARTMENT OF ENERGY under Contract DE-AC06-76RLO 7830}

Printed in the United States of America

Available to DOE and DOE contractors from the

Office of Scientific and Technical Information, P.O. Box 62, Oak Ridge, TN 37831; prices available from (615)576-8401. FTS 626-8401.

Available to the public from the National Technical Information Service,

U.S. Department of Commerce, 5285 Port Royal Rd., Springfield, VA 22161.

NTIS Price Codes, Microfiche A01

Printed Copy

\begin{tabular}{|c|c|}
\hline Pages & $\begin{array}{l}\text { Price } \\
\text { Codes }\end{array}$ \\
\hline $001-025$ & $\mathrm{~A} 02$ \\
\hline $026-050$ & $\mathrm{~A} 03$ \\
\hline $051-075$ & $\mathrm{~A} 04$ \\
\hline $076-100$ & A05 \\
\hline $101-125$ & $A 06$ \\
\hline $126-150$ & $\mathrm{~A} 07$ \\
\hline $151-175$ & A08 \\
\hline $176-200$ & A09 \\
\hline $201-225$ & A 10 \\
\hline $226-250$ & A11 \\
\hline $251-275$ & $\mathrm{~A} 12$ \\
\hline $276-300$ & A13 \\
\hline
\end{tabular}


PNL -7126

UC -245

\title{
LOW-TEMPERATURE CONVERSION \\ OF HIGH-MOISTURE BIOMASS
}

CONTINUOUS REACTOR SYSTEM RESULTS
D. C. Elliott
L. J. Sealock, Jr.
R. S. Butner
E. G. Baker
G. G. Neuenschwander

October 1989

\author{
Prepared for \\ the Biofuels and Municipal \\ Waste Technology Division \\ U.S. Department of Energy \\ under Contract DE-AC06-76RLO 1830
}

Pacific Northwest Laboratory Richland, Washington 99352 

SUMMARY

Pacific Northwest Laboratory (PNL) is developing a low-temperature, catalytic process for converting high-moi sture biomass feedstocks and other wet organic substances to useful gaseous fuels. This system, in which thermocatalytic conversion takes place in an aqueous environment, was designed to overcome the problems usually encountered with high-water-content feedstocks. The process uses a reduced nickel catalyst at temperatures as low as $350^{\circ} \mathrm{C}$ and pressures ranging from 2000 to 4000 psig--conditions favoring the formation of gas consisting mostly of methane. The results of numerous batch tests showed that the system could convert feedstocks not readily converted by conventional methods.

Fifteen tests were conducted in a continuous reactor system to further evaluate the effectiveness of the process for high-moisture biomass gasification and to obtain conversion rate data needed for process scaleup. During the tests, the complex gasification reactions were eval uated by several analytical methods. The results of these tests show that the heating value of the gas ranged from 400 to $500 \mathrm{Btu} / \mathrm{scf}$, and if the carbon dioxide is removed, the product gas is pipeline quality. Conversion of the feedstocks was high. Engineering analysis indicates that, based on these results, a tubular reactor can be designed that should convert greater than $99 \%$ of the carbon fed as high-moisture biomass to a gaseous product in a reaction time of less than $11 \mathrm{~min}$.

A patent is pending on the process, which was developed from basic research sponsored by the Gas Research Institute (GRI). Battelle Development Corporation (BDC) has purchased from GRI the right and title to the invention and patent. Through PNL, BDC has subsequently entered a licensing agreement with Onsite*0fsite, Inc., an engineering firm located in Pasadena, California. Onsite*0fsite is assisting PNL in transferring the technology to the industrial sector.

Future work will concentrate on use of other high-moi sture biomass feedstocks and catalysts to provide data on reaction rates and product yield 
and quality as functions of reactor temperature and pressure, as well as catalyst 1 ifetimes. Additional spinoff work is being conducted for other sponsors to evaluate the process for catalytic conversion of hazardous or waste organics in water to innocuous gases and a clean water stream. 


\section{ACKNOWLEDGMENTS}

This project was performed by Pacific Northwest Laboratory (PNL) under Contract DE-AC06-76RLO 1830 for the U.S. Department of Energy (DOE), Conservation and Renewable Energy. The research was funded by the Biofuels and Municipal Waste Technology Division of DOE and managed through the PNL Biomass Thermochemical Conversion Program. Technical monitoring of the project for DOE was performed by Dr. Don J. Stevens of the Biomass Thermochemical Conversion Program, Technical Field Management Office formerly at PN and currently at the Solar Energy Research Institute, Golden, Colorado. The Technical Field Management Office at PNL was managed by Gary F. Schiefelbein. This project was part of the DOE Thermochemical Conversion Program administered at DOE Headquarters by Simon Friedrich. The authors wish to acknowledge the guidance and support provided by Dr. Stevens and Messrs. Schiefelbein and Friedrich.

Analytical support for this project was provided at PNL by Richard T. Hallen, who operated the gas chromatograph-mass spectrometer and interpreted the chromatographs and spectra.

The authors thank Norman $G$. Banns and staff members at Onsite*0fsite, Inc., for their support, encouragement, and investment in helping to promote the concept and in developing preliminary designs for the 5- and 1-wetton/day processes.

Finally, the authors thank Sue Gano of PNL for her work on the editing and final review of this report and her help in the publication process. 

CONTENTS

SUMMARY. . . . . . . . . . . . . . . . . i i i

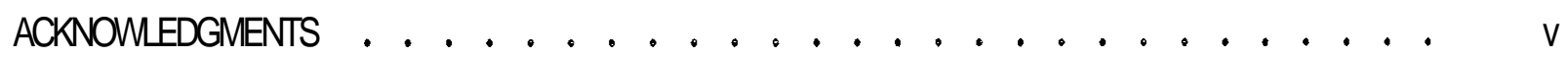

INTRODUCTION . . . . . . . . . . . . . . . . . . . 1

CONCLUSIONS AND RECOMMENDATIONS .................... 3

CONTINUOUS REACTOR SYSTEM ............... 5

MATERIALS TESTED .......................... 5

CRS DESIGN COMPONENTS .................. 6

Feed Pretreatment and Preparation ........ . 6

Reaction Products Separation ............ 11

Instrumentation and Control .......... 12

SAFETY REQUIREMENTS . . . . . . . . . . . . . 16

PROCEDURES . . . . . . . . . . . . . . . . . . . 19

EXPERIMENTAL PROCEDURES . . . . . . . . . . . . . . . 19

Reactor System Operation . . . . . . . . . . 19

Data Acquisition . . . . . . . . . . . 20

ANALYTICAL PROCEDURES ..................... 20

Elemental Analysis............. . 20

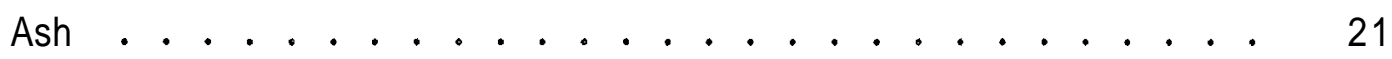

Aqueous 000 Analysis ............. . . 21

Analysis of Dissolved Organics by Gas Chromatography-Mass

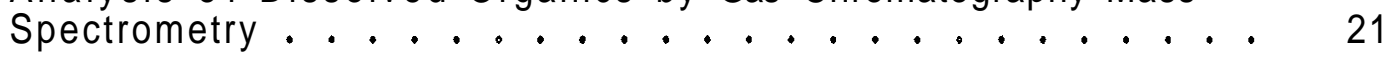

Gas Product Analysis . . . . . . . . . . . . 22 22

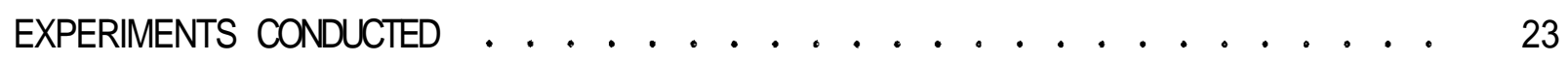

EXPERIMENTAL RESULTS ....................... 25

SORCHUM CONVERSION WITH NICKEL CATALYST . . . . . . . . 25 
EFFECT OF ADDED SODIUM CARBONATE ON CATALYST STABILITY . . . . . 27

RECYCLING OF INCOMPLETELY CONVERTED AQUEOUS STREAM . . . . . . 29

SUCROSE CONVERSION WITH NICKEL CATALYST $\ldots . . . . . . . . . .30$

DISCUSSION OF RESULTS . . . . . . . . . . . . . . . . . 31

PROCESS KINETICS . . . . . . . . . . . . . . . . . 31

CATALYSIS EFFECTS . . . . . . . . . . . . . . . 33

ADDITIONAL RESEARCH ........................ 38

TECHNOLOGY TRANSFER AND PROCESS DEVELOPMENT . . . . . . . . . 41

TECHNOLOGY TRANSFER . . . . . . . . . . . . . . 41

Patent Status and Licensing Agreement . . . . . . . 41

Commercialization .............. 42

Federal Laboratory Consortium Award .......... 43

PROCESS DEVELOPMENT ...................... 45

Tubular Reactor Studies . . . . . . . . . . . 45

Evaluation of Process Economics . . . . . . . . 47

Future Work .............. . . 52

RELATED PUBLICATIONS ......................... 53

REFERENCES ......................... 55

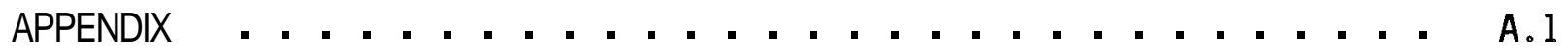




\section{FIGURES}

1 Continuous Reactor System . . . . . . . . . . 7

2 Calibration of Feedstock Tank Level Sensor . . . . . . . . . 9

3 Drawing of Carberry Reactor Internals . . . . . . . . 10

4 Schematic of Data Acquisition and Control System ....... 13

5 Gas Flow Data from Mass Flow Sensor and Wet Test Meter. . . . . 17

6 Kinetic Data in the Continuous Reactor System . . . . . . 32

7 Relationship of Carbon Conversion to Feed Rate ........ 34

8 Relationship of Carbon Conversion to Nickel Concentration in the Reactor .................. 35

9 Conversion as a Function of the Amount of Feedstock Processed . . 36

10 Conversion with Added Sodium Carbonate as a Function of the Amount of Feedstock Processed ............. 39

11 Model of Mobile Pilot Facility ..... . . . . . . . 44

12 Conceptual Flow Diagram of the Thermocatalytic Conversion Process ................... 


\section{TABLES}

1 Parameter Ranges for the CRS Design ........... 8

2 Operational Parameters for the CRS DAC System . . . . . . 14

3 Results of Nickel-Catalyzed Gasification of Sorghum . . . . . . . 26

4 Condensate Analysis for Experiment 7. . . . . . . . . 26

5 Analyses of Solid Products from Catalytic Gasification . . . . 28

6 Results with Added Sodium Carbonate . . . . . . . . . . . . . . 28

7 Results After Extended Operating Time ........... 29

8 Results with Recycled Aqueous Feedstock . . . . . . . . . . . 29

9 Results for Catalytic Gasification of Sucrose . . . . . . . . 30

10 Design Factors for CRS and PDU Tubular Reactors . . . . . . . 47

11 Comparison of Current Fuel Costs and Waste Disposal Costs

for Selected Industries ................ 


\section{INTRODUCTION}

Pacific Northwest Laboratory (PNL) (a) is developing a proprietary thermochemical system that has important technical and economic potential as a method for converting high-moisture feedstocks to methane. This system uses low temperatures, high pressure, and a reduced nickel catalyst to produce fuel gas from feedstocks that cannot readily be converted in conventional systems. An earl ier report, Sealock et a1. (1988), described the background and development of the process, as well as the results of batch reactor tests.

The advantage of the PNL process is that it can be employed without drying or dewatering the feedstock, as conversion takes place in an aqueous environment. Conventional thermal gasification processes, which require temperatures above $750^{\circ} \mathrm{C}$ and air or oxygen for combustion to supply reaction heat, generally cannot utilize feedstocks with moisture contents above $50 \mathrm{wt} \%$; consequently, the conversion efficiency is greatly reduced as a result of the drying step. For this reason, anaerobic digestion or other bioconversion processes have traditionally been used for gasification of high-moisture feedstocks. However, these processes suffer from slow reaction rates and incomplete carbon conversion.

The thermocatalytic conversion concept has developed significant industrial interest and has numerous potential spi noff applications. Onsite*0fsite, Inc., a private turnkey engineering design and construction management firm located in Pasadena, California, has obtained the 1icense for the technology and is assisting PNL in transferring the technology to industry. Technology transfer of the process to industry is expected to be an important part of future research efforts.

This report is based on tests conducted in 1988 in a continuous reactor system (CRS), which provided conversion rate data needed for scaleup and documented the reaction chemistry on a continuous basis. The work for both the batch reactor tests and the CRS tests was conducted under the project,

(a) Operated for the U.S. Department of Energy by Battelle Memorial Institute under Contract DE-AC06-76RLO 1830. 
"Low-Temperature Thermochemical Conversion of High-Moisture Biomass Feedstocks to High-Valued Fuels," which was sponsored by the U.S. Department of Energy (DOE), Conservation and Renewable Energy through its Biofuels and Municipal Waste Technology Division.

Results are presented in this report for 15 continuous reactor system tests. During these tests, high-moisture biomass was efficiently converted to medium-Btu fuel gas. The gasification system operated at temperatures of $350^{\circ} \mathrm{C}$ to $400^{\circ} \mathrm{C}$ and pressures of 2000 to 4000 psig to attain high rates of conversion and high methane yields. A discussion of the results is provided, along with an overview of future work and technology transfer applications. 


\section{CONCLUSIONS AND RECOMMENDATIONS}

The CRS tests provided useful information on the kinetics of the conversion of high-moisture biomass feedstocks to gases. For example, for sorghum, carbon conversion of more than $80 \%$ was achieved at $400^{\circ} \mathrm{C}$. Gas compositions with nickel catalyst usually ranged up to $40 \% \mathrm{CH}_{4}$ (methane), $45 \%$ to $55 \% \mathrm{CO}_{2}$ (carbon dioxide), and $15 \%$ to $25 \% \mathrm{H}_{2}$ (hydrogen). The heating value of the gas produced was typically in the range of 400 to $500 \mathrm{Btu} / \mathrm{scf}$. This information can be used to design a tubular reactor system, which is expected to achieve greater than $99 \%$ conversion and produce pipeline quality gas (after removal of carbon dioxide byproduct).

The addition of an alkali carbonate catalyst had significant impacts on both the rate of reaction and the product composition. For complex 1ignocellulosic feedstocks, such as sorghum, the addition of sodium carbonate increased the rate of reaction based on carbon conversion to gas. In the case of less complex feedstocks, such as sucrose, the addition of alkali appeared to reduce the rate of reaction. In both cases, the gas product composition was changed to include more hydrogen and carbon dioxide and less carbon monoxide and hydrocarbons. There was also an indication of enhanced catalyst lifetime, which should be further investigated.

Tests with sucrose as a model biomass feedstock also produced useful information for designing commercial systems. The rate of sucrose conversion was similar to that observed for model compounds ( $p$-cresol and methyl isobutyl ketone). These results demonstrate that high conversion rates will be obtainable in appropriately designed reactor systems. This information further confirms our understanding of the activity of nickel catalyst to convert water solutions of carbohydrates to methane and carbon dioxide gas.

Low-temperature, high-pressure, catalytic gasification appears to be a useful means of energy recovery from many types of biomass. This approach requires much less reactor volume and residence time and produces less solid byproduct than anaerobic digestion. It is also more responsive to load changes and more robust with respect to feedstock variations. 
The CRS should be operated with other high-moisture biomass feedstocks to provide the valuable chemical and engineering data required for process optimization. The data should include reaction rates and product yield and quality data as functions of reactor temperature and pressure, as well as catalyst 1 ifetimes.

Other tests should include model compound experiments to test specific mechanisms of reaction. Detailed reactor model ing would be facilitated by more in-depth knowledge of the chemical mechanisms occurring in the system.

Tests in a plug-flow tubular reactor are needed to verify the high conversion of high-moisture biomass and the applicability of the kinetic data obtained in the CRS to more conventional large-scale reactor designs. The information developed in the CRS should be used for future scaleup of the process. Furthermore, a technical and economic assessment of the concept should be made based on the test results. 


\section{CONTINUOUS REACTOR SYSTEM}

The CRS was built to collect data that could not readily be generated in a batch-operation reactor. The primary objectives of the CRS experiments were as follows:

- Obtain accurate, isothermal kinetic data for a range of feedstocks.

- Determine catalyst lifetime and deactivation rates.

- Collect data at a broader range of pressure and temperature conditions than was feasible using the batch reactor system.

- Demonstrate, on a small scale, the viability of various feedstock pretreatment and feeding options, including thermal hydrolysis of the biomass to facilitate pumping of the slurry.

- Study the effect of biomass solids concentration on product quality and yield, and on catalyst lifetime.

The experimental program originally envisioned in this project was not completed when rimited funds within the Biofuels and Municipal Waste Technology Division of DOE were reallocated. Instead, only 15 tests with biomass feedstock were performed in the CRS. Other startup tests and related tests with sucrose as the feedstock are described in this report. The appendix contains a summary of the experiments, listing operating conditions and limited results. Other early tests were conducted in the CRS with food processing wastes and solutions of hazardous waste model compounds and are reported elsewhere (Baker et a1. 1989a,b).

\section{MATERIALS TESTED}

The three feedstocks tested in the CRS were cellulose, sucrose, and sorghum. The cellulose was a microcrystalline TLC reagent-grade material from Baker Chemical Co. (Lot \# 745383). The sucrose was reagent-grade crystalline sucrose packaged by Spectrum Chemical Co. (Lot \# 61156D04). The sorghum was a freshly cut Sorghum $X$ Sudan hybrid grown north of Pasco, Washington. The material was hand-cut and shredded into approximately 1 -in. pieces before it was wrapped in 30 -gal plastic bags and placed in $1-\mathrm{ft}^{3}$ waxcoated cardboard boxes. The sorghum was stored in a walk-in refrigerator at 
$2^{\circ} \mathrm{C}$ until used. Some of the sorghum used in these experiments showed signs of spoilage, which occurred when it warmed to room temperature during an extended refrigeration failure.

The nickel catalysts used in the experiments were Ni1404 and 6-65 R/S. The Nil404 catalyst, produced by Harshaw, is a reduced and stabilized nickel metal on a proprietary support. According to the manufacturer's specifications, it contains $68 \%$ nickel, has a surface area of $125 \mathrm{~m}^{2} / \mathrm{g}$ and is manufactured as $3 / 16-i n$. tablets. The 6-65 R/S catalyst, produced by United Catalysts, is a reduced and stabilized nickel metal catalyst on a refractory support. According to the manufacturer's specifications, it contains $27 \%$ nickel and is manufactured as $1 / 4-i n$. tablets. The surface area of this catalyst is not reported by the manufacturer but is expected to be much less than the high surface area support of the Ni1404. Other tests with these two catalysts in the CRS have demonstrated a difference in physical stability between the two catalysts (Baker et al. 1989a). The 6-65 R/S, having a ceramic support and a higher proportion of support material, is a much harder catalyst and is less susceptible to softening and disintegrating in the reaction environment.

In addition to the nickel catalyst, sodium carbonate was added in some experiments to determine the effect of alkali on the catalyzed reactions. The sodium carbonate used in these experiments was reagent-grade anhydrous powder packaged by Baker (Lot \# 143082).

\section{CRS DESIGN COMPONBNIS}

The CAS was composed of six major functional subsystems: feed pretreatment and preparation; pumping; reactor; reaction products separation; instrumentation and control; and product analysis. The system was based on a throughput of 0.5 to 10 pounds of biomass slurry per hour, and was typically operated over a range of 0.5 to $1.0 \mathrm{lb} / \mathrm{h}$. Other system design parameters are shown in Table 1. The entire system is shown schematically in Figure 1.

\section{Feed Pretreatment and Preparation}

Feedstock pretreatment and preparation in a batch mode was designed to ensure that a relatively homogeneous mixture of biomass was fed to the 


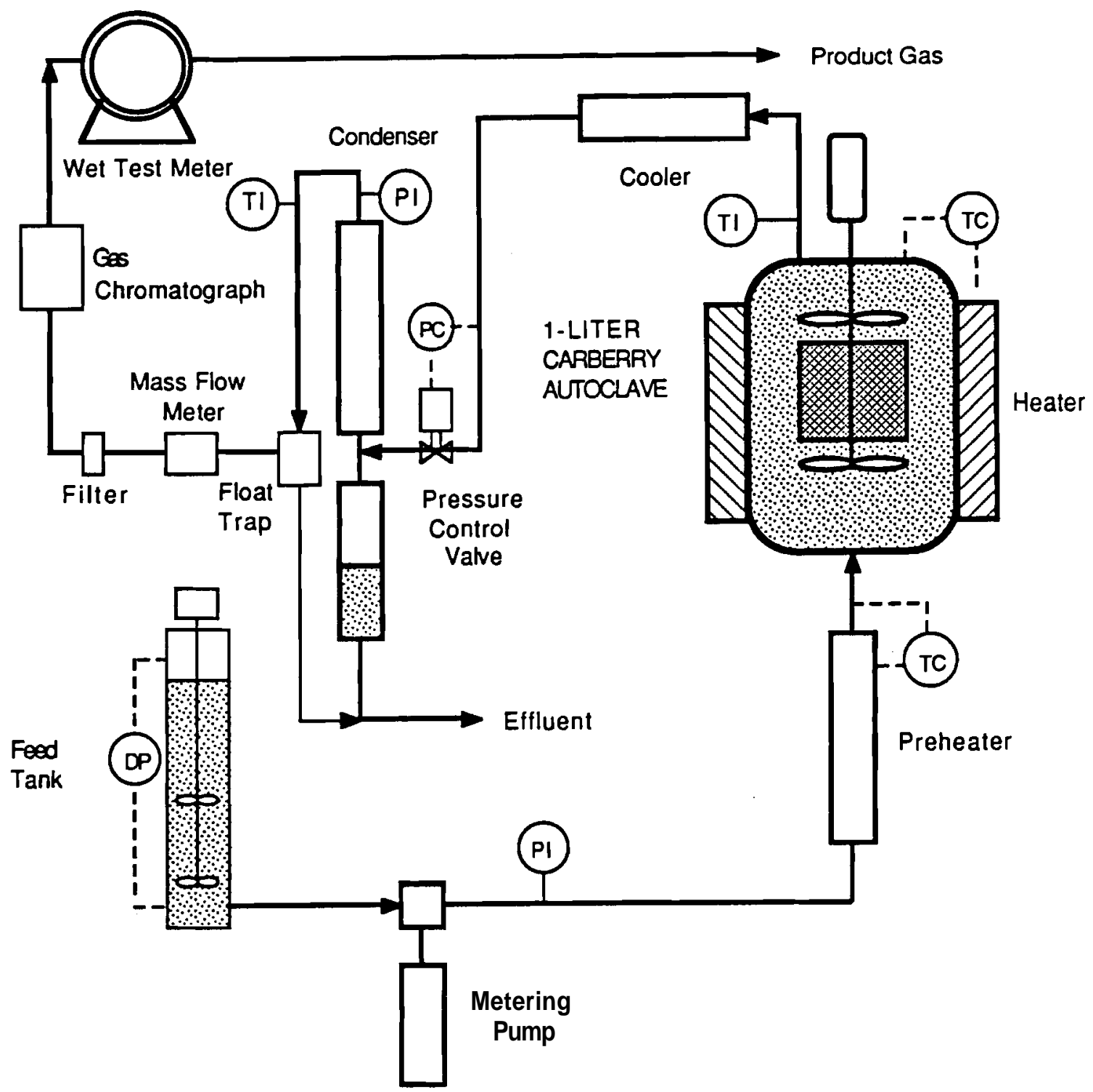

FIGURE 1. Continuous Reactor System

reactor. Size reduction of the feedstock was also required because the CRS pumping system was unable to operate on feed slurries containing particles larger than approximately 0.125 in. maximum dimension.

For sorghum slurries, a Union Process 2.5-gal agitated media attrition mil 1 (Model $1-S$ ) with 0.25 -in. -diameter $\times 0.5$-in. diagonally cut stainless steel media was used to wet-mill the sorghum material to -18 mesh. A small 
TABLE 1. Parameter Ranges for the CRS Design

Design Parameter
Temperature
Pressure
Reactor Type
Residence Time
Throughput

$\frac{\text { Design Ranqe }}{300^{\circ} \mathrm{C} \text { to } 420^{\circ} \mathrm{C}}$
1200 to $6500 \mathrm{psig}$
wel1-stirred autocl ave (CSTR) (a)
$<5$ to $60 \mathrm{~min}$
0.25 to $5 \mathrm{~L} / \mathrm{h}$ slurry

(a) Continuous stirred-tank reactor.

electric garden shredder was used before milling to coarse-chop the sorghum in order to facilitate storage and fine grinding. The slurries were prepared in 1.1-gal batches and required blending at approximately $600 \mathrm{rpm}$ for 15 to $30 \mathrm{~min}$. Deionized water was added to achieve the desired consistency. Slurries containing between 4 and $6 \mathrm{wt} \%$ solids were found to work best. Feedstock slurries were screened four times through an 18 mesh screen, and material that did not pass the screen was removed between screenings.

For cellulose and sucrose, feed preparation involved simply stirring the feedstock or blending the feedstock with deionized water. Unfortunately, the cellulose slurries thus produced were subject to rapid settling, which interfered with consistent pumping of the feed. Adequate stirring in the feed tank was not available at the time of the early cellulose experiments. Attempts to produce more stable cellulose slurries by processing in the attrition mill or by the addition of corn starch were not successful. Pumping

The pumping subsystem was designed to operate at feed pressures up to 6000 psig and flow rates between 0.2 and $4.0 \mathrm{~L} / \mathrm{h}$. A Milton Roy Mil royal A reciprocating, packed-pl unger, positive-displacement pump was used to meet this objective. Because the pump was equipped with check valves containing 3/8-in.-diameter balls, size reduction of the feedstock was particularly important with fibrous feedstocks such as sorghum. System piping included 0.5-in. (0.065 wall) 304 stainless steel tubing on the outlet of the pump. 
Pump inlet piping was 0.5 -in. (0.035 wall) 304 stainless steel tubing. All valves and valve trim (except the pressure-control valve) were also made of stainless steel.

Slurry flow rates were not measured directly because a flow meter that would work at low flow rates and high pressures could not be obtained. Instead, the flow rate was calculated by measuring the rate of level change on a cal ibrated glass feed tank that was equipped with a mill imeter scale along the side. An approximate tank level could also be measured using a differential pressure transducer (Setra Model C228-1), which was configured as shown in Figure 1. The upper leg of the transducer was open to the atmosphere, while the lower leg was subject to the pressure of the liquid static head generated by the column of feedstock slurry in the tank. Correlation between the two readings was generally good, as shown in Figure 2, but a correction factor would be required to make the readings useful.

\section{$\underline{\text { Reactor }}$}

The reactor vessel used for the experiments was a 1-L Carberry spinningbasket autoclave (Figure 3). This vessel was chosen because it was capable of safe operation at relatively high pressures and temperatures (2000 to $6000 \mathrm{psig}$ and $350^{\circ} \mathrm{C}$ to $450^{\circ} \mathrm{C}$ ); it was compatible with aqueous alkali salts

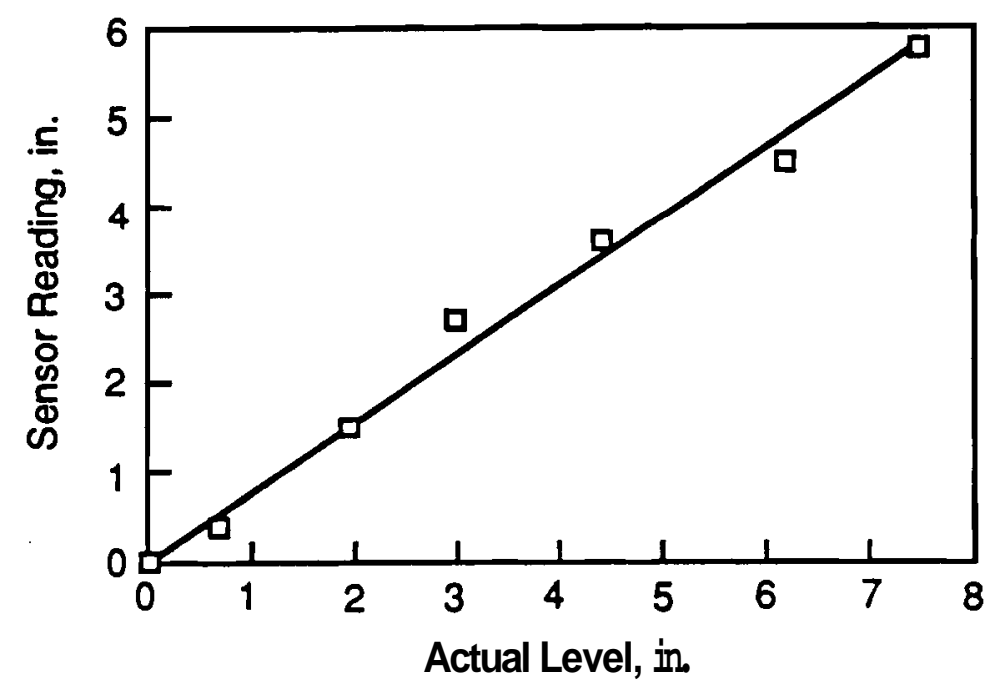

FGURE 2. Calibration of Feedstock Tank Level Sensor 


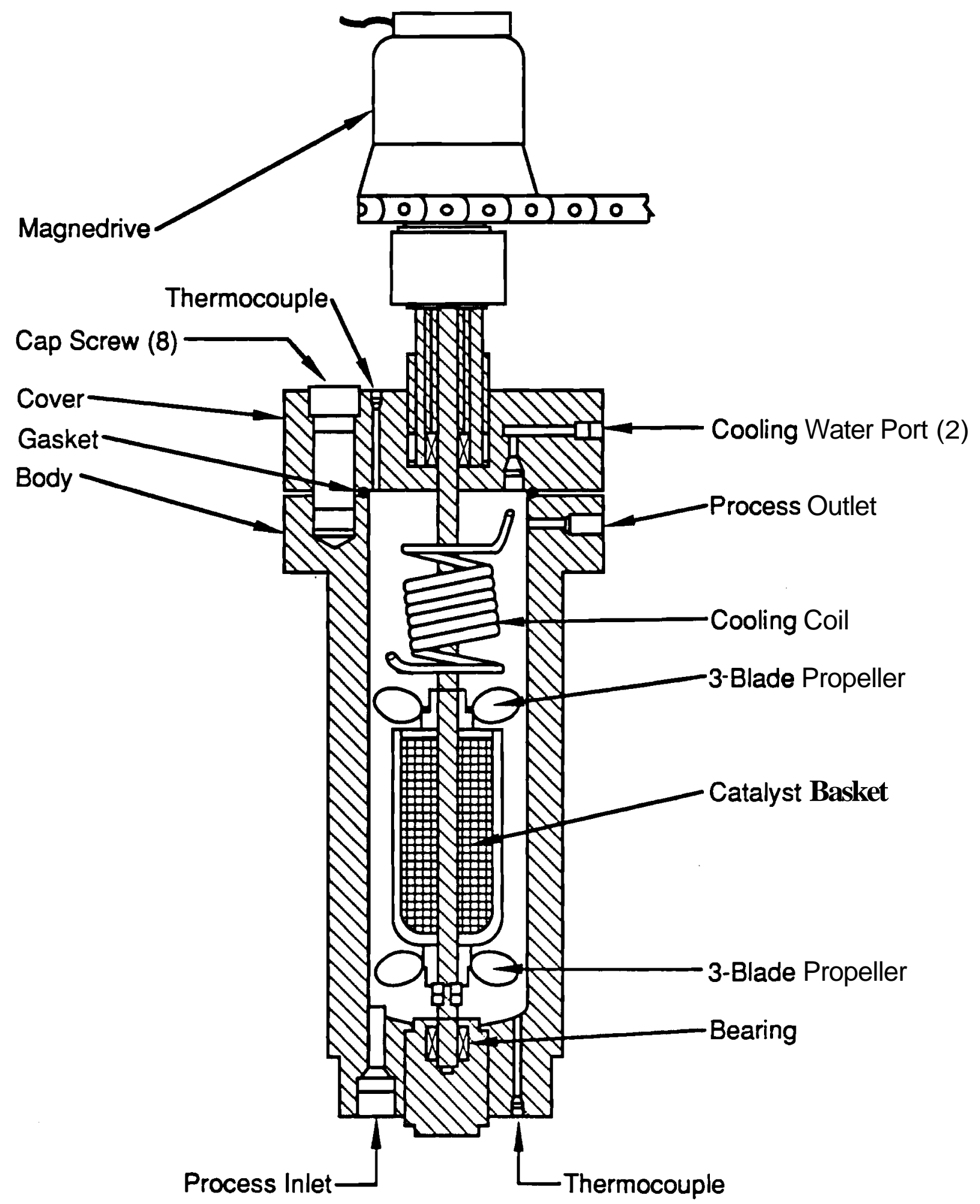

FIGURE 3. Drawing of Carberry Reactor Internals 
(such as sodi um carbonate); and had a well-characterized flow/mixing profile inside the vessel. The reactor vessel and its wetted components were fabricated from Inconel 600 . The catalyst was loaded into a wire basket (about $150 \mathrm{~mL}$ in volume), which rotated around a central axis. The reactor was gradientless (i sothermal and uniform concentration throughout) because the high-speed rotation of the catalyst basket and impellers ensured that heat and mass transfer did not limit the rate of reaction. Consequently, this reactor was ideal for obtaining true reaction rate data. A further advantage is that kinetic parameters obtained with this reactor can in turn be used to design other types of reactors, such as a tubular reactor, which are of more practical interest for larger-scale systems.

The reactor subsystem also included equipment to heat the reactor to reaction conditions and a preheater column. The reactor furnace was a 3.4-kWe resistance heater. The preheater was a 9/16-in.-diameter (0.102 wall) tube, 38 in. long, equipped with a $400-\mathrm{W}_{e}$ resistance heater. The preheater was capable of heating the feed slurry to approximately $200^{\circ} \mathrm{C}$ at normal feed rates of 0.5 to $1.0 \mathrm{~L} / \mathrm{h}$. The preheater was found to be unnecessary during early tests and its use was discontinued. Charring of feedstock in the preheater was noted on some occasions particularly with sugar-containing feedstocks, which were judged to be more susceptible to thermal degradation.

Pressure was controlled in the reactor by a Badger Meter Research Control Valve. Piping downstream from the reactor was 0.25 in. in diameter with thick-wall (0.049 in.) tubing before it reached the pressure letdown valve and thin-wall (0.035 in.) tubing after the valve. The valve itself contained a 3/32-in. orifice (trim size 0 ). The valve stem and seat were made of stellite. Early experiments with a smaller trim size (P6, 1/16-in. orifice) resulted in plugging of the valve.

\section{Reaction Products Separation}

Separating the reaction products, which included an aqueous phase and (sometimes) a tar or oil phase, in addition to the gaseous products, was an important task in the overall design of the reactor system. The downstream processing of the gas consisted of quenching the reactor products, separating 
the liquid phases from the gaseous products, and sampling each phase for analysis. Gas analysis was considered the most critical element in determining reactor material balances, and was done either on a continuous basis or via grab samples.

Separation of phases was effected in a 24-in. x 0.5-in. -diameter-tube, vertical secondary condenser/separator. Products were cooled in a primary condenser and reduced in pressure over the pressure control valve before they entered the separator. Although the secondary condenser was originally expected to significantly impact the cooling of the product stream, in most cases little secondary cooling was needed. Early in the startup of the system the secondary condenser was packed with stainless steel shot, but the packing later proved to be unnecessary because it acted primarily as a tar trap. Most of the liquid products were removed via the bottom of the separator; however, significant carryover of water into the offgas stream led to flooding of the gas analysis system on several occasions. As a means to eliminate this problem, a Balston floattrap (Type 20-211) was added after the secondary condenser, as well as a T-type filter (Balston Type 95S6) with a 0.02- $\mu \mathrm{m}$ hol low fiber membrane fi7ter. The floattrap was self-draining, and the secondary condenser was drained manually. Condensate product from both drains was collected in a liquid receiving tank mounted on an electronic load cell with a \pm 1 -g precision.

A liquid sample loop, upstream of the secondary condenser, allowed recovery of small volumes of liquid product before it could mix in with the other condensate in the collecting vessel. These samples were believed to be representative of the reactor contents.

Instrumentation and Control

In a flow system, many variables must be controlled, and a great deal of data must be collected. In order to accommodate the complexity, advantage was taken of the advances in computerized data acquisition, which has become much more cost effective in recent years. The data acquisition and control (DAC) system employed in the CRS was a hybrid personal computer (PC)-based system employing discrete data acquisition devices and single-loop process controllers communicating to a central PC via RS232 serial communications 
1 ines. The PC was. used during experiments to monitor the process, cal ibrate instruments, and record data onto an ASCII disk file for later analysis. A custom-built, QuickBASIC program was used to coordinate these activities. Commercially available software was not used because there were no programs available at the time of design that could supply device drivers for all of the different equipment having to be monitored during a run. Figure 4 shows a schematic diagram of the system in its most recent configuration. Table 2 lists the operational parameters of the system.

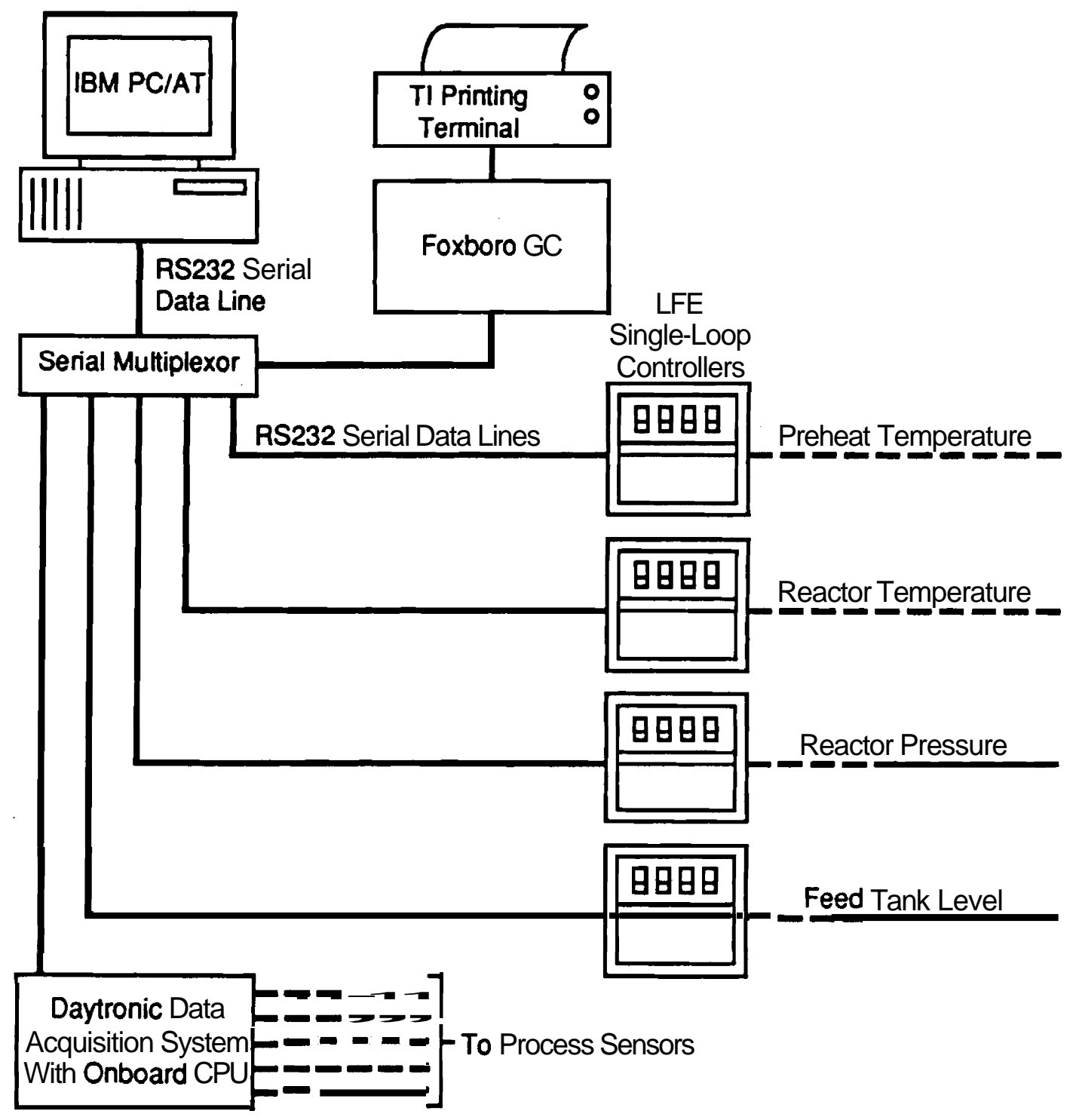

FIGURE 4. Schematic of Data Acquisition and Control System 
TABLE 2. Operational Parameters for the CRS DAC System

Parameter

Number of Channels (installed)

Number of Channels (capacity)

Communications Rate

Data Resolution

Data Collection Cycle Time

Data Collection Cycle Time (typical)

Data Logging Frequency
Val ue

19

no $\operatorname{limit}(a)$

1200 baud

12 bit except controllers; controllers were 8 bit

1.5 to $60 \mathrm{~s}$

(software selected)

$1.5 \mathrm{~s}$

$1 /$ min

(a) Although there were no hardware-imposed limits on the system, its performance deteriorated with additional serial interface connections. For supervisory operation, the upper practical limit was probably no more than eight serial devices. However, the devices could include serial-communicating data acquisition systems like the Daytronics with capacities of up to 64 discrete channels.

Distributed, single-loop control by stand-al one controllers was selected to provide additional safety in the event of a DAC system failure, and to el iminate some of the computational overhead which would have otherwise been the responsibility of the DAC software. The controllers were LFE 2000 series devices, operating with 8-bit data resolution, 1-s display refresh times, and, in some cases, automatic loop tuning. Although controller set points and control constants could be changed remotely on these devices, this feature was not implemented. Communications to the PC was via RS232 interface operating at 1200 baud. One notable feature of the control scheme was the use of a pneumatic valve actuator on the pressure control valve. This option was selected in favor of an electric actuator because of the much quicker response rate of the pneumatic device. A current-to-pressure transmitter was used to allow the use of a microprocessor-based controller with the air actuator.

The control lers were operated in an overdamped mode, which slowed response somewhat, but helped to minimize oscillation around the set point and almost eliminated overshoot of the control point following a change in 
set point. This latter characteristic was particularly important with the pressure control valve, because even momentary excursions above the system pressure limits would cause the safety rupture disk to vent the system contents to the pressure relief line and terminate or delay the run.

The gas analysis was performed by a Foxboro Model 931C industrial process gas chromatograph (GC), which is described elsewhere in the report. The Foxboro GC was tied to the PC through an RS232 serial interface. At regular intervals (approximately every $10 \mathrm{~s}$ ), the Foxboro would transmit a single burst of data, which contained system status codes and current gas composition data. The cycle time on the Foxboro was roughly 5 min, so data transmitted between analyses simply repeated the previous analysis. The string transmitted by the Foxboro was parsed to extract the needed data. Other communications features, including reconstruction of chromatograms, were available but not implemented in the system because of time and cost constraints on software development. The 10-s lag between data transmissions caused some delays because the DAC software would "wait" for a new transmission each time; this would cause a perceptible pause in the screen updating, which normally took place every $1.5 \mathrm{~s}$. This problem was minimized by rewriting the DAC software to cause the Foxboro to be interrogated only before each logged data point (typically every $60 \mathrm{~s}$ ).

The Foxboro was operated through a Texas Instruments printer/terminal device, and the printed records of all gas analyses were maintained as experimental records along with the manual data collection sheets. This device was connected through a second RS232 serial port, and permitted the operator to calibrate the instrument or change operational parameters from the terminal keyboard.

Noncontrol sensors such as thermocouples and the gas mass flow meter were monitored via a Daytronics System 10 data acquisition unit. This device consisted of a central chassis and processor board, along with a number of special-purpose data acquisition boards designed for specific types of signals (i.e., T/C, 4-20 ma, 0-5 V). The Daytronics system processed all raw signals to engineering units before sending the data to the PC for recording. Use of this system permitted a number of data channels to be relayed via a 
single RS232 serial port, and permitted additional computing overhead to be shifted from the main PC to the Daytronics CPU.

The controllers, the Foxboro GC, and the Daytronics unit were tied to the PC via an eight-port serial device multiplexor of the type used for connecting multiple terminals to a single printer. This device scans any data sent to it for embedded control characters, which can be used to direct the data from the computer to any of the eight serial input/output ports. Incoming data are buffered in approximately $1 \mathrm{~K}$ of RAM, which is available on the multiplexor board. A second multiplexor is available on the system and can be daisy-chained to the first to expand the number of serial devices that can be connected to the system.

The system included three separate control loops. Each of these loops was run from the PC-based DAC system, which also kept a record of all uncontrolled variables. Electronic pressure transducers were used to monitor all recorded pressures, and conventional mechanical (i ndication-only) gauges were used in other, noncritical applications, such as the instrument air lines. Al1 temperatures were monitored by Type "K" thermocouples.

Product gas flow rate was measured by a thermal conductivity, mass flow sensor (Porter, Series 100F). The unit was calibrated to nitrogen gas ( 0 to 10 standard liters per minute), but actual flow rates of mixed gases could be calculated based on known calibration factors and known gas composition. The product gas also flowed through a wet test meter to determine the total flow of gas. The wet test meter readings and the mass flow sensor readout are compared in Figure 5. The mass flow sensor data are plotted both in the raw uncalibrated form and as corrected for the appropriate gas composition.

\section{SAFETY REQUIREMENTS}

Safe operation of the high-pressure reactor system was a top priority. Before the tests began, the high-pressure reactor system and the laboratory facility (where it is located) underwent a safety analysis and review, including evaluation of the equipment by staff members responsible for safety 


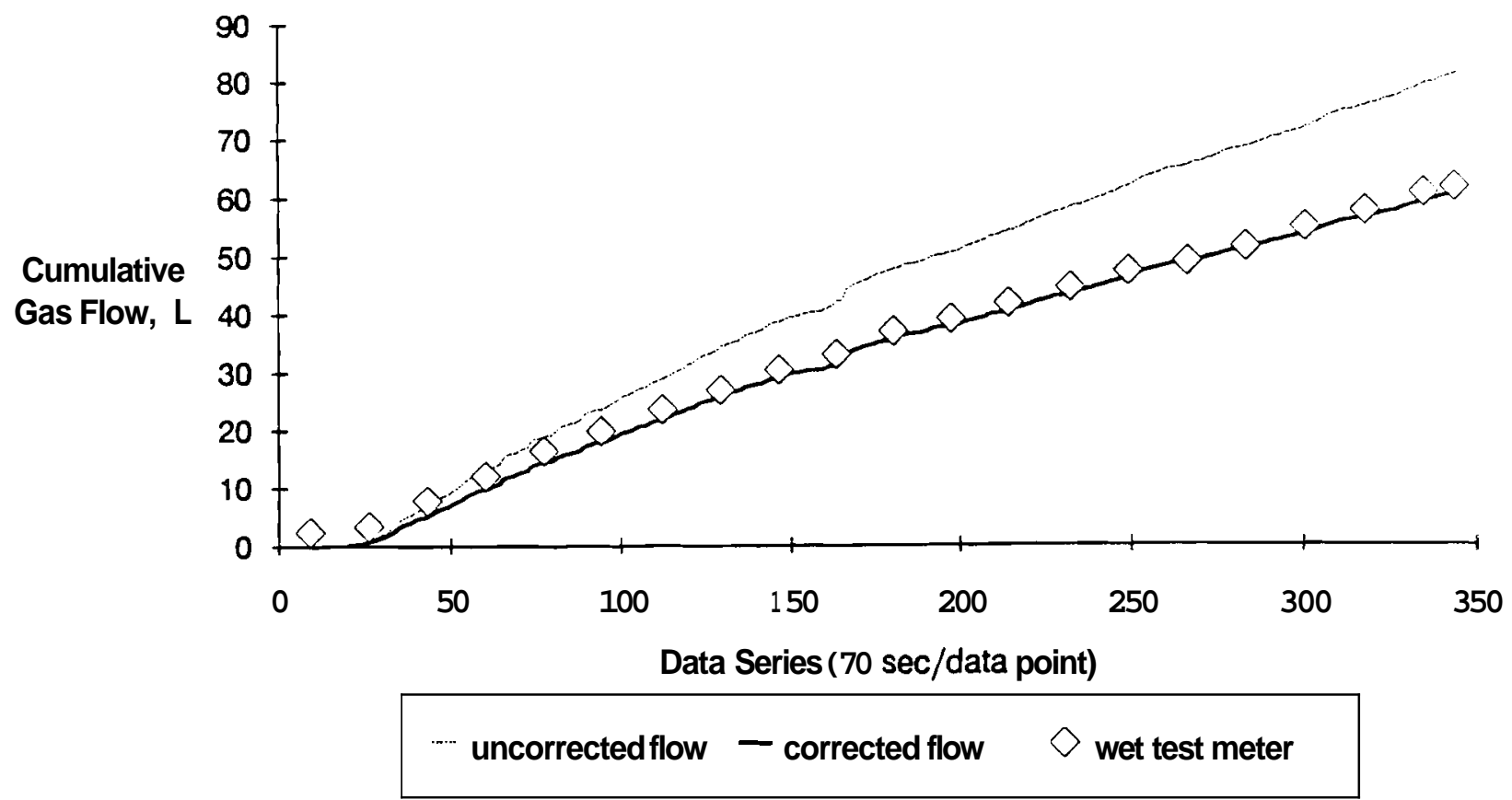

FIGURE 5. Gas Flow Data from Mass Flow Sensor and Wet Test Meter

and pressure systems engineering. A Safety Evaluation Document was prepared, as were Safe Operating Procedures.

Several safety features were built into the CRS design, including specification of fail-safe valves to prevent overpressure situations in the case of control system failure, manual depressurizing capability, and use of relief valves and vented rupture disks. A steel barricade was built around critical components to further shield operators in the event of system failure. All appropriate quality assurance and safety procedures and guidelines concerning pressure vessel certification and operation were consulted and incorporated into the Standard Operating Procedures document.

An equally important step in ensuring operator safety was the requirement of a specialized safety training session for all potential operators. This session was developed in cooperation with PNL safety engineers. 



\section{PROCEDURES}

This section describes the experimental and analytical procedures used for the CRS tests.

\section{EXPERIMENTAL PROCEDURES}

Before each experiment, enough biomass was taken from cold storage to prepare 6 to $7 \mathrm{~L}$ of slurry consisting of approximately $5 \%$ biomass solids. Deionized water was used to bring the moisture content up to the desired level during the milling operation described in the feed pretreatment and preparation section. A small portion of the slurry was withheld for a precise determination of its moisture content.

\section{Reactor System Operation}

The catalyst basket was first loaded with the specified amount and type of catalyst, and distilled water (approximately $100 \mathrm{~mL}$ ) was loaded into the reactor vessel. The reactor then was sealed, and the low-pressure end of the system was pressure-checked with nitrogen. While the system was pressurized, the calibration of all system pressure transducers was verified by comparing their readouts with a calibrated mechanical gauge. The high-pressure end of the reactor system was then pressure-checked with nitrogen, and the purge gas was vented'from the system. The initial supply of prepared feedstock was then loaded into feed vessel.

The system controllers were set to manual with zero output before the initial set points were programmed into each controller. The alarm points were then set on all controllers. The furnace controller was turned "ON" by pressing the START/STOP key until the "MAN" Iight turned off and the furnace began to heat.

When the reactor had heated to within $50^{\circ} \mathrm{C}$ of its set point, the preheater furnace was activated, if desired. During heatup the tachometer on the catalyst basket driver was used to set the spin rate for the basket. Also, the pump stroke length was set and the pump primed by opening a priming valve and allowing the pump suction to be flooded to displace air and fill the outlet lines. When the system had heated to operating temperature, the 
feed was diverted into the reactor system by closing the priming valve. Feed rates, temperatures, and pressures were controlled throughout the experiment while products were recovered and quantified. Cooling water flow to the condensers and driver shaft cooling lines was maintained throughout the experiment.

To terminate an experiment, the feed pump was stopped, cooling water was passed through reactor cooling coils, and the reactor furnace and preheater controllers were turned to the "OFF" (MAN) position. The feed tank was then emptied. Pressure was usually left overnight in the reactor during cooldown. Run data were recorded in Laboratory Record Books, and computerized run data were archived on floppy disk.

\section{Data Acauisition}

The system operation was straightforward, although the program was not as rigorous as intended and failed on a few experiments because of 1 ine noise or improper shutdown sequence. The data were time-stamped with the PC system time, and recorded on disk as a series of ASCII records listing the individual data points in a preselected sequence. Each line in the data file corresponded to a single data record, and could easily be read into a spreadsheet file for later analysis and viewing. A major limitation of the system was the inability to view archived data during data acquisition. Most of the newer commercial software now provides this capability.

\section{ANALYTICAL PROCEDURES}

A number of analytical procedures were required in this project to understand the complex gasification reactions occurring during the testing of these high-moisture feedstocks.

\section{El emental .Analysis}

Perkin-Elmer (P-E) 2400 and 240B analyzers were used for analysis of carbon, hydrogen, nitrogen, and oxygen. The P-E 2400 determines carbon, hydrogen, and nitrogen by detecting and measuring their combustion products $\left(\mathrm{CO}_{2}, \mathrm{H}_{2} \mathrm{O}\right.$, and $\left.\mathrm{N}_{2}\right)$. Combustion occurs in pure oxygen under static conditions. Helium is used to carry the combustion products from the combustion 
furnace through the reduction tube (which reduces any $\mathrm{NO}_{\mathrm{x}}$ ) and through a chromatography column and the thermal conductivity detector. The 2400 contains a calculator component that determines the elemental composition from a millivolt signal based on a reference compound, acetanilide. For the 240B, used for oxygen analysis, a separate sample must be pyrolyzed in helium over platinized carbon so that oxygen is converted to carbon monoxide. The carbon monoxide is scrubbed free of acid gases and then oxidized and measured as carbon dioxide. The instrumental readout is in millivolts, which is used to calculate the oxygen content based on reference compounds (benzoic acid and sucrose).

Ash

Ash of the dried feedstock was determined by combustion in a muffle furnace similar to ASTM Method D1102-84, which covers determining ash from wood. Porcelain crucibles with Iids were used throughout.

\section{Aqueous COD Analvsis}

The aqueous feedstocks and products were analyzed for chemical oxygen demand (COD). The COD measurements were made with the HACH closed reflux micromethod. In this system, approved by the U.S. Environmental Protection Agency, prepackaged reagents are reacted with the sample in the HACH $\mathrm{CO}$ reactor. The proper amount of I iquid effluent sample was added to HACH $\infty O$ digestion reagent vials and then digested at $150^{\circ} \mathrm{C}$ for $2 \mathrm{~h}$. The $\mathrm{COD}$ was measured by placing the vial (after digestion) in a DR/3 spectrophotometer and reading the $\infty 00$ from a calibrated scale that reads directly in $\mathrm{mg} \operatorname{COD} / \mathrm{L}$. Analysis of Dissolved Orqanics by Gas Chromatography-Mass Spectrometry

The chromatography column was a $30 \mathrm{~m} \times 0.25 \mathrm{~mm}$ ID, DB-5 wall-coated, open tubular, silica capillary purchased from $\mathbb{B} W$ Scientific, Inc. The column was contained in a Hewlett-Packard (HP) 5890 GC directly coupled with an HP5970 mass selective detector (MSD). The HP splitless injection system was used with an injector temperature of $300^{\circ} \mathrm{C}$ and an injection port pressure of 15 psig with helium carrier gas. The column temperature was programmed to $300^{\circ} \mathrm{C}$ at $10^{\circ} \mathrm{C} /$ min with a starting temperature of $40^{\circ} \mathrm{C}$. The portion of the column passing through the transfer zone between the GC and the MSD was 
maintained at $300^{\circ} \mathrm{C}$. The $70-e v$ electron impact spectra were recorded from 20 to $300 \mathrm{~m} / \mathrm{e}$ at a scan rate of $250 \mathrm{amu} / \mathrm{s}$. One-microliter injections were used for these analyses.

Gas Product Anal vsis

Gas product analysis was used to determine material balances and conversion rates around the reactor system. The gaseous stream was principally composed of $\mathrm{CO}_{2}, \mathrm{CH}_{4}, \mathrm{H}_{2}$, and $\mathrm{C}_{2}{ }^{+}$hydrocarbons, as well as water vapor. The gas analysis equipment was able to measure these gas concentrations with reasonable accuracy and precision on a near-continuous (real-time) basis with a very short ( $t 5 \mathrm{~min}$ ) turnaround. This rapid turnaround was important to establishing steady-state operation during relatively limited duration experiments and helped in minimizing the assumptions made when determining material balances around the reactor. In the CRS, a thermal conductivitybased detector was used in the GC analyzer (Foxboro 931C). The Foxboro unit was directly compatible with the DAC, which would allow actual gas composition to be factored into the calibration of the gas mass flow meter in real time, permitting more accurate flow rate determination. However, real-time calibration was not accomplished during the term of this project.

A secondary means of product gas analysis was by dedicated GCS for gas composition determination. Two separate Carle automatic gas chromatograph (AGC) units were used. A thermal conductivity detector (Model 158A) was used to analyze gases incl uding hydrogen, carbon oxides, oxygen, nitrogen, methane, ethane, and ethylene. A flame ionization detector (Model 357A) was used to measure hydrocarbon vapor $\left(C_{1}\right.$ to $\left.C_{6}\right)$ concentrations. 


\section{EXPERIMENIS CONDUCTED}

Initial system testing of the CRS (Experiments A and B) began in March 1988 when water alone was processed through the reactor containing nickel catalyst. These tests were conducted to verify system operation and control. Specifically, these tests served as pumping and pressure checks for the system and tested the heaters, controllers, and data acquisition system. Since no biomass was fed, no gas product was formed; therefore, the product recovery systems were not tested.

Experiments 1 through 4 were made with cellulose as the biomass model feedstock. These experiments tested the slurry feeding system and the gas recovery system. Experiment 1 was terminated when a leak developed. Experiment 2 was terminated because of plugging in the let-down valve. Experiment $3 \mathrm{a}$ was terminated when the reactor furnace burned out. Experiments $3 \mathrm{~b}$ and 4 were not successful because of the inconsistent feeding observed as a result of settling of the cellulose from the water carrier. Condensate carryover into the gas analysis system was noted in all of these experiments.

The valve plugging problem was overcome by changing the trim in the valve to a larger orifice size. Also, a technique was developed wherein the valve was manually instructed to open in order to blow the orifice clear. Such a maneuver could be used to dislodge small particulates at the first signs of a pressure buildup. The condensate carryover problem was el iminated by the addition of the floattrap and line filter. Consistent feeding of microcrystalline cellulose was never achieved because of the too rapid settling of the particles.

Experiments 5 to 15 were performed with the sorghum feedstock. Experiments 5 and 6 were terminated early in the run because of pumping difficulties after only limited data acquisition. However, in these experiments the problem was due to air pockets in the slurry which caused loss of prime in the pump and plugging of the check valves by pieces of stem. In later experiments, satisfactory feeding was achieved for slurries of approximately $5 \mathrm{wt} \%$ solids by careful control of agitation in the feed tank and sieving of 
the slurry. Experiments 7 and 8 were successful tests of the process. Experiment 9 was performed with a low concentration slurry, which was more difficult to pump. Experiments 10 to 12 were successful tests of different catalyst concentrations and feed rates. Experiment 13 was performed with aqueous condensate from Experiments 10 to 12 as the feedstock. Experiment 14a was terminated because of feeding difficulties, and Experiment 14b was abandoned because the catalyst basket driver was not turned on during the experiment. Experiment 15 was a successful experiment with sodium carbonate added to the feedstock. Experiments 06 and $\mathbf{0 7}$ were performed with sucrose as the feedstock. In all of these preliminary experiments, important information was gained in the operation and control of the CRS and in the appropriate steps required in producing a pumpable feedstock. 


\section{EXPERIMENTAL RESULTS}

Useful processing results were obtained with two feedstocks, sorghum and sucrose. These experiments were performed with nickel metal catalyst at feedstock concentrations of $2 \%$ to $10 \%$ solids in water at $400^{\circ} \mathrm{C}$ and 4000 psig. Other experiments with added sodium carbonate, with reduced levels of nickel catalyst, and with a recycled aqueous feedstock were also performed.

\section{SORGHM CONVERSION WITH NICKEL CATALYST}

Data from Experiments 5 through 10 can be evaluated to determine the activity of nickel catalyst in the catalytic gasification of sorghum. In addition, results are available from a single test with a more dilute sorghum feedstock (2.6\% solids in Experiment 9 vs. about $5 \%$ in other tests) and a test (Experiment 11) in which half of the nickel catalyst was replaced by alumina balls. One baseline, uncatalyzed experiment was also performed (Experiment 12). Processing rates and results for these experiments are presented in Table 3. Carbon conversion to gas is based on carbon in the gas product compared with carbon in the feedstock. Reduction in $\infty 00$ is based on the $\infty 00$ in the liquid effluent compared with the $\infty$ in the feedstock. The difference in the two numbers apparently results from insoluble tars or solids that are not accounted for in the $\infty 0$ analysis of the effluent. The results presented in Table 3 are for activity at an early stage of the experiment and represent the high activity of the fresh catalyst. In later stages of the experiment, catalyst activity was reduced (unlike results reported earlier for hazardous chemical destruction, Baker et al. 1989b). Results with the catalyst after several hours on stream are discussed in the section on sodium carbonate addition.

Product streams from the experiments were analyzed in a number of ways. The gas product was measured continuously and its composition analyzed by the Foxboro gas analyzer and by chromatographic analysis on an intermittent basis. The aqueous condensate stream was sampled periodicall y and measured for $C O D$. In some cases, solids in the condensate were also recovered by filtration and elemental composition determined. Catalytic activity was monitored by evaluation of these product measurements. Table 4 lists some 
TABLE 3. Results of Nickel-Catalyzed Gasification of Sorghum

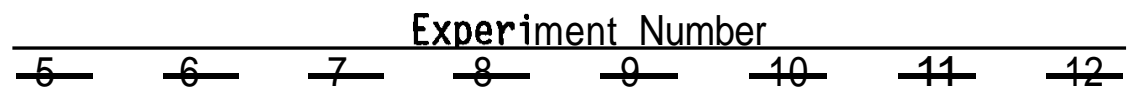

$\begin{array}{lllllllll}\text { Feed, wt\% dry solids } & 6.6 & \mathbf{5 . 1} & \mathbf{4 . 7} & \mathbf{5 . 6} & \mathbf{2 . 6} & \mathbf{5 . 6} & \mathbf{5 . 8} & \mathbf{5 . 8} \\ \text {, g COD/L } & 93.0 & 79.5 & \mathbf{7 5 . 0} & \mathbf{8 9 . 0} & \mathbf{4 0 . 5} & \mathbf{8 9 . 0} & \mathbf{8 3 . 0} & \mathbf{8 2 . 0} \\ \text { Feed Rate, mL/h } & 504 & 592 & 500 & 324 & 585 & 648 & 593 & 572 \\ \text {, g COD/h } & 46.9 & 47.1 & 37.5 & 28.8 & 23.7 & 57.7 & 49.2 & 46.9 \\ \text { Effluent, g COD/L } & 25.0 & 15.4 & 15.2 & 20.0 & 14.4 & 38.1 & 35.7 & 35.0 \\ \text { Reduction of COD, \% } & 73 & 80 & 82 & 85 & 70 & 57 & 62 & 63 \\ \begin{array}{l}\text { Carbon Conversion } \\ \text { to Gas, \% }\end{array} & 53 & 42 & 46 & 56 & 81 & 34 & 27 & 22 \\ \end{array}$

TABLE 4. Condensate Analysis for Experiment 7

Time Total Sample, $\mathrm{g}$ Drv Solids. q Solids. \% $10: 45$

11: 15

$11: 45$

$12: 20$

$12: 45 \quad 16.2511$

13: 15

$13: 45 \quad 13.2541$

$14: 15$

$14: 45$

15: 15

$15: 45$

16: 15

16.5718

0.0137

0.0191

0.0109

0.0052

0.0008

$\frac{\text { CD. Dom }}{15200}$
27400 (26800) (a)
35000

36000

0.082

36000

$35000(38000)(b)$

34000

\footnotetext{
(a) 00 of solids-free aqueous only.

(b) Most of the solids $(-50 \%$ to $80 \%)$ remained in the vial as a tar-like material that could not be scraped out.
} 
typical condensate product analysis data (from Experiment 7). These data show that the amount of insoluble solid carryover into the condensate is quite low at all levels of catalyst activity, while the $\infty 0$ loading increases throughout the experiment.

The spent catalyst from these experiments was also analyzed to determine the extent of carbon deposition. The results are presented in Table 5. Carbon deposition appears to be inconsequential from a material balance standpoint except possibly in Experiment 15, which was performed with added sodium carbonate. Also included in Table 5 are analyses of the solids and tars collected from the condensate stream. It is clear from these results that the solids in the condensate are not particles of catalyst that were carried out of the reactor, but are primarily solidified tar products. Some nickel catalyst may be incorporated in the condensate solids (at most $30 \%$ by weight), but no analysis for nickel in the solids or tars has been performed.

\section{EFFECT OF ADDED SODIUM CARBONATE ON CATALYST STABILITY}

Two tests (Experiments 14 and 15) were run to determine the effect of added alkali on the nickel catalyst. Useful results were obtained only in Experiment 15 because of inconsistent feeding and lack of stirring in Experiment 14. An operating hypothesis was that the addition of sodium carbonate could modify the activity of the nickel catalyst to improve the reaction rate or to maintain the high reaction rate seen in the early stages of the experiments as described above. Results from Experiment 15 are presented in Table 6. 
TABLE 5. Analyses of Solid Products from Catalytic Gasification, wt\%

\begin{tabular}{|c|c|c|c|c|}
\hline \multirow{2}{*}{ Fresh G-65R/S Catalyst } & $\underline{\text { Carbon }}$ & Hvdrogen & Nitrogen & Oxygen \\
\hline & 3.0 & 0.6 & 0.0 & \\
\hline \#5 Spent Catalyst & 2.0 & 0.5 & 0.0 & \\
\hline \#6 Spent Catalyst & 2.4 & 0.2 & 0.5 & \\
\hline \#7 Spent Catalyst & 4.3 & 0.2 & 0.0 & \\
\hline \#8 Spent Catalyst & 3.8 & 0.2 & 0.0 & \\
\hline \#9 Spent Catalyst & 2.1 & 0.1 & 0.0 & \\
\hline \#10 Spent Catalyst & 2.8 & 0.2 & 0.0 & \\
\hline \#11 Spent Catalyst & 2.8 & 0.3 & 0.0 & \\
\hline \#13 Spent Catalyst & 3.3 & 0.1 & 0.0 & \\
\hline \#15 Spent Catalyst & 6.1 & 0.4 & 0.0 & \\
\hline \#7 11:15 Effluent Solid & 50.6 & 6.3 & 2.5 & 13.1 \\
\hline \#7 12:45 Effluent Solid & 52.5 & 7.2 & 2.2 & \\
\hline \#7 13:45 Effluent Solid & 50.1 & 7.9 & 1.6 & \\
\hline \#10 Condensate Tar/Solids & 56.8 & 6.5 & 2.5 & 13.7 \\
\hline \#12 Filtered Solids & 61.8 & 7.3 & 2.9 & \\
\hline \#12 Tar, Condensate Tank & 73.2 & 7.9 & 4.3 & \\
\hline \#15 Solids & 50.0 & 5.9 & 0.9 & \\
\hline \#15 Tar & 77.8 & 8.6 & 1.8 & \\
\hline
\end{tabular}

TABLE 6. Results with Added Sodium Carbonate

$\begin{array}{lll}\text { Feed, wt\% dry solid } & \underline{15 a} & \frac{15 b}{} \\ , \text { g COD/L } & 72.0 & \approx 5 \\ \text { Feed Rate, } \mathrm{mL} / \mathrm{h} & 506 & 514 \\ , \mathrm{~g} \mathrm{COD} / \mathrm{h} & 36.4 & 37.0 \\ \text { Effluent, g COD/L } & 20.0 & 37.0 \\ \text { Reduction of COD, \% } & 73 & 56 \\ \text { Carbon Conversion } & 71 & 52 \\ \text { to Gas, \% } & & \end{array}$


The change in activity from 15a to 15b (see Reduction of $\infty 0$ and Carbon Conversion to Gas in Table 6) can be compared with the changes after extended operating time as seen in other experiments by comparing Table 3 and Table 7. This change will be discussed later in this report.

TABLE 7. Results After Extended Operating Time

\begin{tabular}{|c|c|c|c|}
\hline & $7 \mathrm{~b}$ & $8 b$ & $10 b_{-}$ \\
\hline $\begin{aligned} \text { Feed, } & w t \% \text { dry solid } \\
& \text { g COD/L }\end{aligned}$ & $\begin{array}{l}4.7 \\
75.0\end{array}$ & $\begin{array}{l}5.6 \\
89.0\end{array}$ & $\begin{array}{l}5.6 \\
89.0\end{array}$ \\
\hline $\begin{aligned} \text { Feed Rate, } & \mathrm{mL} / \mathrm{h} \\
& \mathrm{g} \mathrm{COD} / \mathrm{h}\end{aligned}$ & $\begin{array}{l}511 \\
38.3\end{array}$ & $\begin{array}{l}332 \\
29.5\end{array}$ & $\begin{array}{l}845 \\
75.2\end{array}$ \\
\hline Effluent, $g \mathrm{COD} / \mathrm{L}$ & 35.0 & 32.0 & 36.0 \\
\hline Reduction of $\mathrm{COD}$, \% & 62 & 77 & 68 \\
\hline $\begin{array}{l}\text { Carbon Conversion } \\
\text { to Gas, \% }\end{array}$ & 29 & 40 & 25 \\
\hline
\end{tabular}

\section{RECYCLING OF INCOMPLETELY CONVERTED AQUEOUS STREAM}

A single test (Experiment 13) used the aqueous byproduct from previous experiments as feedstock. The feedstock for the test was a mixture of $3.7 \mathrm{~L}$, $1.3 \mathrm{~L}$, and $1.1 \mathrm{~L}$ of collected condensate from Experiments 10, 11, and 12, respectively. The $\infty \mathrm{O}$ of the feedstock was determined by a weight average of the CODs of the three condensates. No carbon concentration was determined for the'feedstock. Results of the test are presented in Table 8.

TABLE 8. Results with Recycled Aqueous Feedstock

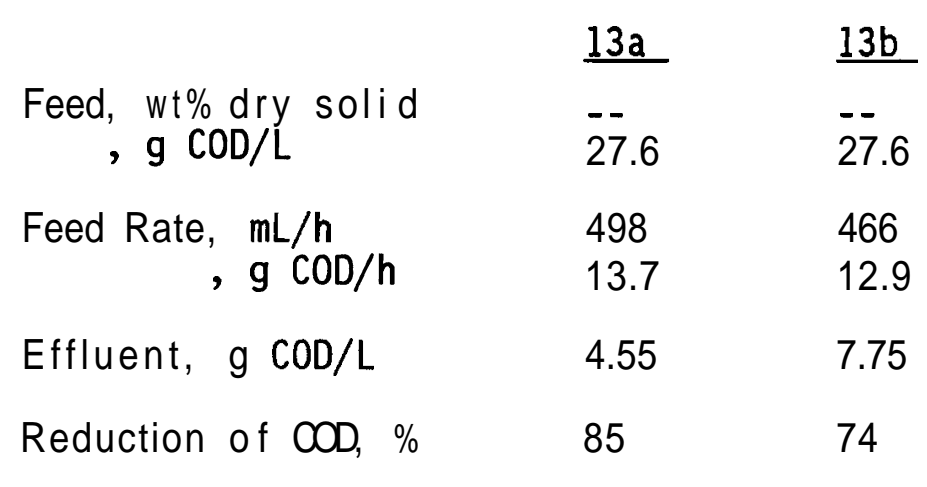


SUCROSE CONVERSION WITH NICKEL CATALYST

The results of two experiments with sucrose as the feedstock are reported here since sucrose is a useful model for carbohydrate structures found in high-moisture biomass. The results of the two tests, 06 with nickel only and 07 with added sodium carbonate, are presented in Table 9. The results show high conversion rates for the sucrose with only slight evidence of catalyst deactivation. With the added sodium carbonate, the reaction rate is significantly reduced. The catalyst deactivation is similar to that seen in the sodium-free system.

TABLE 9. Results for Catalytic Gasification of Sucrose

\begin{tabular}{|c|c|c|c|c|c|}
\hline & \multicolumn{5}{|c|}{ Experiment Number } \\
\hline & $\underline{06 a}$ & $\underline{06 \mathrm{~b}}$ & $06 \mathrm{c}$ & $\underline{07 a}$ & $\underline{07 \mathrm{~b}}$ \\
\hline $\begin{aligned} & \text { Feed, } \text { wt } \% \text { dry solid } \\
& \text { g COD } / L\end{aligned}$ & $\begin{array}{r}10 \\
116\end{array}$ & $\begin{array}{r}10 \\
116\end{array}$ & $\begin{array}{r}10 \\
116\end{array}$ & $\begin{array}{r}10 \\
115\end{array}$ & $\begin{array}{r}10 \\
115\end{array}$ \\
\hline $\begin{aligned} \text { Feed Rate, } & \mathrm{mL} / \mathrm{h} \\
& \mathrm{g} \mathrm{COD} / \mathrm{h}\end{aligned}$ & $\begin{array}{l}570 \\
66.1\end{array}$ & $\begin{array}{l}600 \\
69.6\end{array}$ & $\begin{array}{l}900 \\
104.4\end{array}$ & $\begin{array}{l}569 \\
65.4\end{array}$ & $\begin{array}{l}561 \\
64.5\end{array}$ \\
\hline Effluent, $g \mathrm{COD} / \mathrm{L}$ & 5.8 & 6.7 & 15.5 & 22.0 & 29.0 \\
\hline Reduction of $\infty \mathrm{D}, \%$ & 95 & 94 & 88 & 83 & 77 \\
\hline $\begin{array}{l}\text { Carbon Conversion } \\
\text { to Gas, } \%\end{array}$ & 85 & 92 & 87 & 68 & 63 \\
\hline
\end{tabular}




\section{DISCUSSION OF RESULTS}

The results of this limited program can be better evaluated by comparing them with results of similar experiments in two companion programs (Baker et al. 1989a,b). Those programs involved tests with water solutions of organic chemicals as models for hazardous wastes and tests with food processing wastes, another type of high-moisture biomass.

\section{PROCESS KINETICS}

The process kinetics were evaluated on the basis of 000 in the feedstock and the product condensate and on a carbon basis as measured in the feedstock and the product gas. The effect of temperature or pressure was not evaluated in this study because of the unexpected early termination of the project.

All tests were performed at approximately $400^{\circ} \mathrm{C}$ and 4000 psig (see appendix for specific operating conditions for each experiment). The evaluation of kinetics is therefore limited.

The order of the reaction and the rate constant can be determined by plotting the log of the rate of the conversion against the log of the reactant concentration in the reactor (Figure 6). This kinetic information can be used to design other types of reactors, such as a fixed-bed tubular reactor, which are of more practical interest for commercial systems where high conversion is desired. The limited data obtained with sorghum are not sufficient to determine the order of the reaction or the rate constant. However, numerous experiments completed in the CRS with p-cresol can be used for comparison (Baker et al. 1989b).

As shown in Figure 6, the conversion of p-cresol is first order (slope $=0.99 \mathrm{M} .14$ ) with a rate constant of $3.25 \mathrm{~min}^{-1}$ at $400^{\circ} \mathrm{C}$. The required residence time in a plug-flow tubular reactor can be calculated from the following equation for first-order reactions:

$$
T=-\ln \left(1-X_{a}\right) / k
$$




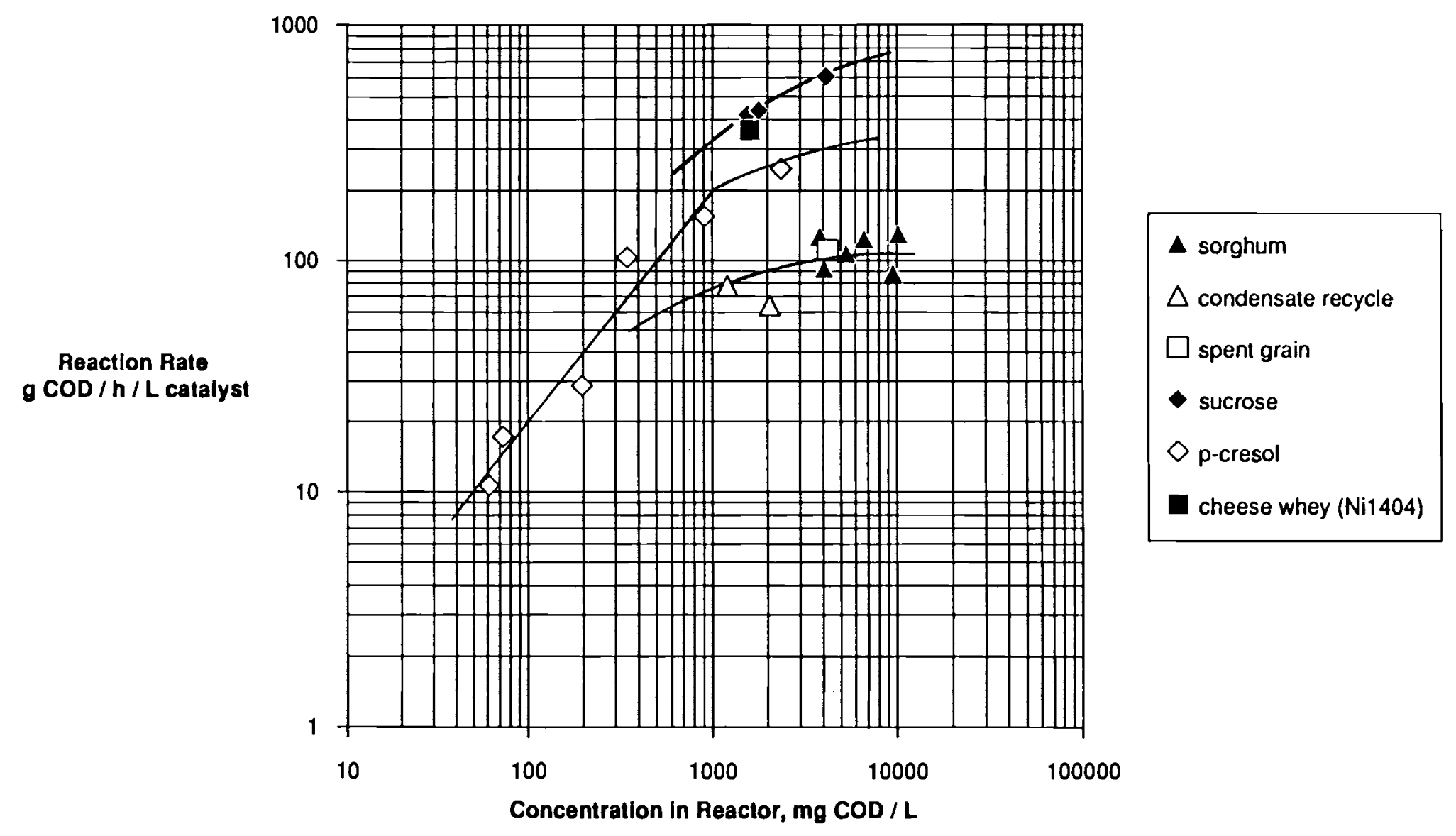

FIGURE 6. Kinetic Data in the Continuous Reactor System 
where $\mathrm{T}$ is the required residence time, $\mathrm{Xa}$ is the fractional conversion, and $\mathrm{k}$ is the first-order rate constant. Using this expression, the required residence time for $99 \%$ conversion of $\mathrm{p}$-cresol in a plug-flow tubular reactor would be $1.4 \mathrm{~min}$.

There is some indication that the conversion might not be truly first order at higher concentrations and might tend toward zero order. Experimental data with $\mathrm{p}$-cresol at $350^{\circ} \mathrm{C}$ support this view (Baker et a1. 1989b). One explanation for the perceived zero-order kinetics is that the surface of the catalyst is saturated with organic and the rate is purely a function of the turnover frequency of the catalyst. Assuming that the first-order p-cresol model is appropriate for the sorghum feedstock at low concentration ( $<1000 \mathrm{ppm}$ COD), the estimated residence time can be calculated on firstorder kinetics at low concentration and zero-order kinetics at higher concentration. For 99\% conversion of a sorghum slurry at 5\% solids $(20,000 \mathrm{ppm}$ COD reactor conditions), the residence time would increase by 9.5 min over the first-order p-cresol model. This calculation represents a worst case and is essentially the maximum required residence time.

From the limited data obtained with other feedstocks (Figure 6), it appears that sucrose and cheese whey (primarily lactose) react somewhat faster than p-cresol. Sorghum and spent grain, on the other hand, react somewhat slower. The difference in reaction rates suggests that the conversion of the lignin fraction of the feedstock or its pyrolysis products is the rate-limiting step.

As a corollary, Figure 7 shows the relation between the rate of feed to the reactor and the conversion represented as product gas carbon produced from carbon in the feedstock. A definite downward trend is noted over the range of feed rate studied. This trend indicates a limitation on reaction sites, suggesting catalyst saturation.

\section{CATALYSIS EFFECTS}

Additional information on the effect of catalyst concentration in the reactor also suggests a catalyst-limited reaction in the range studied. The relation of carbon conversion (to gas) to the amount of nickel in the reactor 


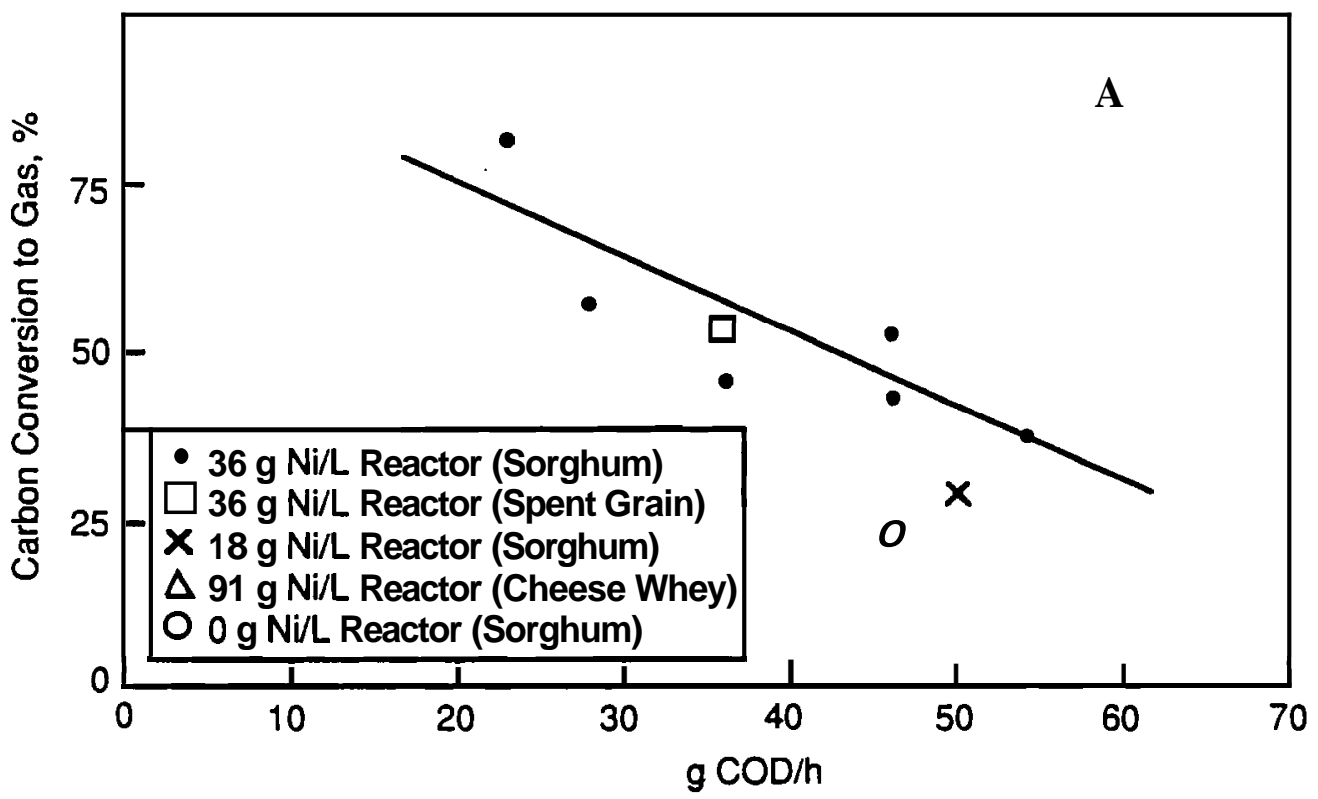

FGURE 7. Relationship of Carbon Conversion to Feed Rate

is depicted in Figure 8. The data points are for experiments all at about the same feed rate. The highest nickel concentration is attained through the use of a high concentration nickel catalyst (Ni1404), while the other concentrations occurred with the $665 \mathrm{R} / \mathrm{S}$ catalyst with different amounts of alumina balls to replace catalyst. Clearly, the conversion to gas is limited by the amount of nickel available as catalyst.

The data obtained in the sorghum experiments show a steady decline in carbon conversion to gas and a deterioration in gas composition (occurring over a period of several hours) during each experiment. These results are similar to the loss in COD reduction efficiency reported by Baker et al. (1989a) when using spent grain or cheese whey as the feedstock and contrast sharply with the results when using organic model compounds such as p-cresol or methyl isobutyl ketone (Baker et a1. 1989b). Li kewise, the sucrose experiments reported here show no significant loss in reactivity as a function of time. These results are plotted in Figure 9. The final plateau for the carbon conversion in the sorghum cases is essentially that found with no catalyst added to the system. 


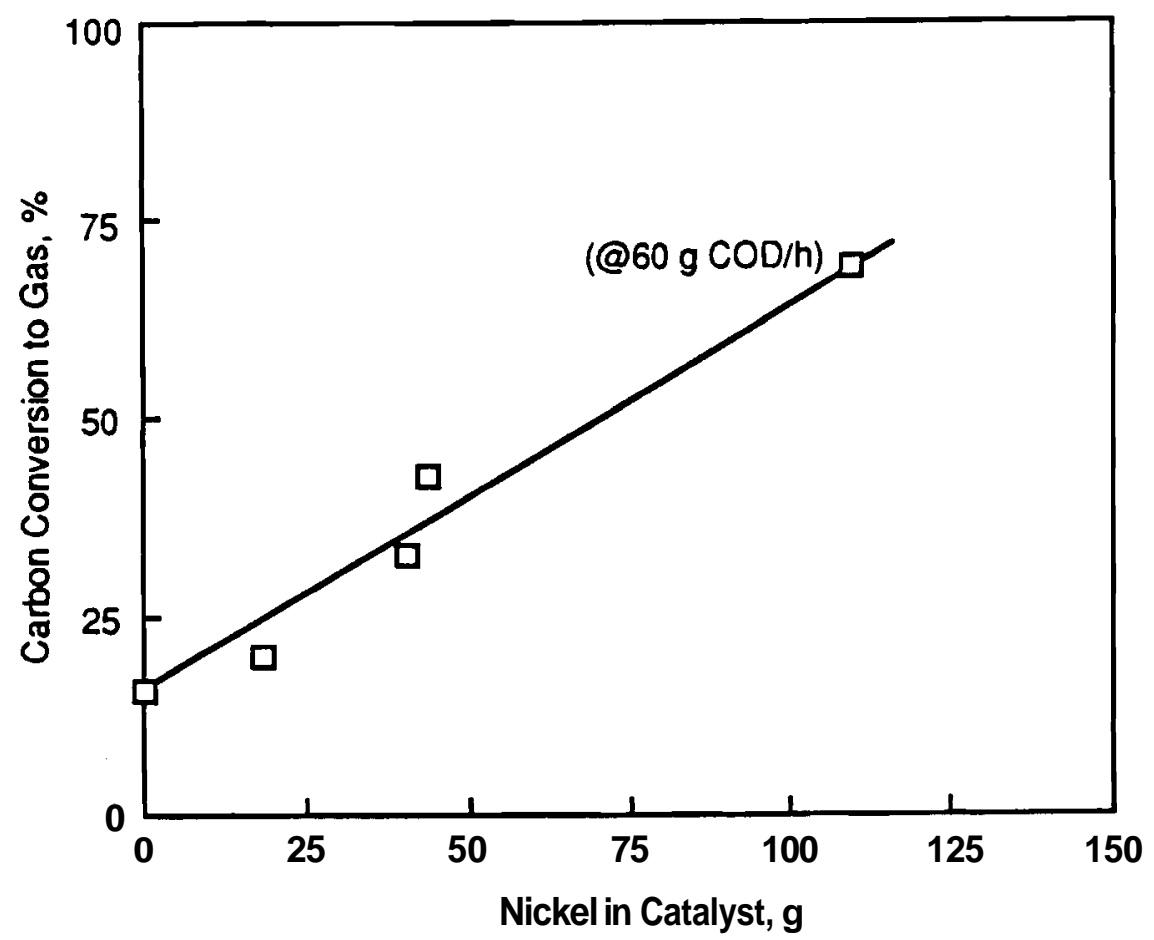

FIGURE 8. Relationship of Carbon Conversion to Nickel Concentration in the Reactor (@ 45 to $50 \mathrm{~g} \mathrm{COD} / \mathrm{h}$ feed rate)

The loss of catalyst activity could have occurred for a number of reasons. The tests were performed at higher concentration of organic loading in the reactor than those reported earlier for aqueous organic waste destruction (Baker et al. 1989b). Saturation of the catalyst surface with organic materials could lead to accumulation of deposits and eventual fouling. However, analysis of the catalysts after the experiments using sorghum as feedstock showed little evidence of carbon deposition (see Table 5). Analysis of the effluent condensate has determined that the highest concentrations of unconverted organic constituents are the small organic acids followed by phenols and cyclopentenones. The latter two groups are similar to that reported earlier in high-pressure liquefaction experiments (Elliott, Sealock, and Butner 1988). The acids cause the low pH (4.0) measured in the condensate. Under acid conditions the decomposition of carbohydrates to hydroxymethyl furfural (HMF) becomes favorable (Nel son, Hal len, and Theander 1988). 


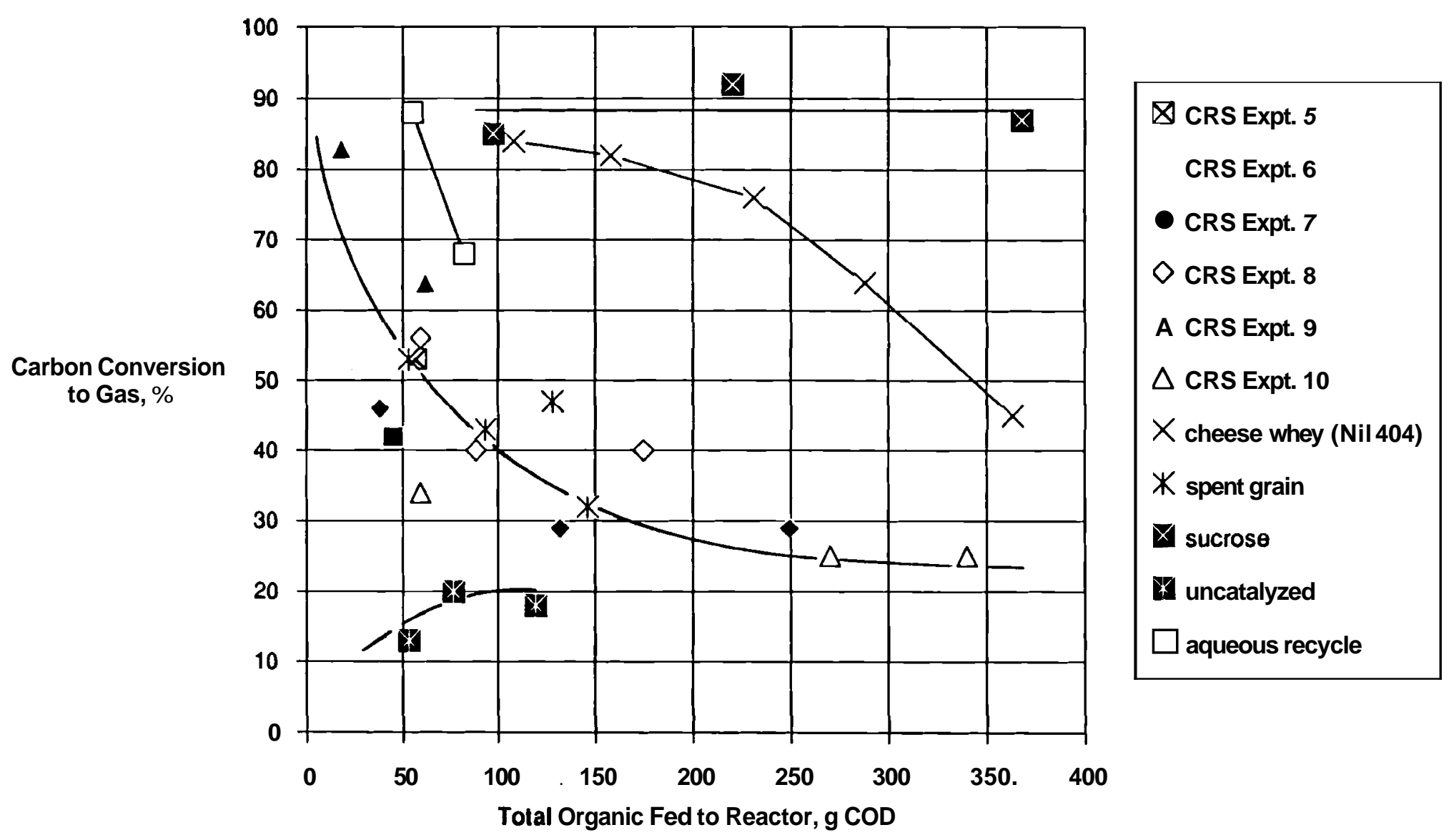

FIGURE 9. Conversion as a Function of the Amount of Feedstock Processed 
When a high concentration of HF is produced, it polymerizes to a black solid with a carbon content of approximately $70 \%$. This solid appears to be similar to the black solid recovered in some of the experiments (see Table 5). The catalyst deactivation could have been caused by the polymerization of HMF on the active sites of the catalyst. If the $\mathrm{pH}$ could be kept closer to neutral by the decomposition of the organic acids as fast as they are produced, HMF production and polymerization would not be a problem. In the experiments with sorghum, the production of organic acids may have been too fast for the catalyst to decompose them and maintain near-neutrality in the system. An alternative would be to control the $\mathrm{pH}$ with an added base, such as alkali.

The loss of catalyst activity also could have occurred if the highpressure steam environment in the reactor dissolved either nickel (and removed it from the reactor) or a portion of the support, causing a physical breakdown of the catalyst and a loss of active sites. Analysis of the $\mathbf{G 6 5}$ R/S and the Ni1404 catalysts before and after experiments with methyl isobutyl ketone showed no change in composition of the catalysts. Similar analysis of the $665 \mathrm{R} / \mathrm{S}$ catalyst after an experiment with spent grain as the feedstock also showed no significant change in the major catalyst components. However, the minor inorganic components in the biomass feedstocks, such as alkali, sulfur, phosphorus, chlorine, trace metals, or nitrogen-containing materials could be responsible. In the case of the catalyst used with spent grain, slight increases in sulfur, silicon, phosphorus, zinc, manganese, copper, and potassium were noted. Analysis for nitrogen and sodium has not been sufficiently precise to determine changes in composition; chlorine analysis has not been attempted.

The addition of sodium carbonate to the reactor system was tested for two reasons: 1) early batch tests with low-ash biomass (wood, cellulose, and hollocellulose) indicated that alkali had a positive catalytic effect on the gasification of aqueous biomass slurries in the presence of limited amounts of nickel catalyst, and 2) the addition of alkali based on theoretical arguments could help maintain the catalytic activity of nickel either by minimizing coke formation (as found in conventional methanation systems) or by neutralizing the reaction medium. The experiments showed that the addition of sodium carbonate can have a complex effect on the results. The 
addition of alkali in the sorghum experiment resulted in an improvement in carbon conversion to gas as seen earlier in the batch tests. However, the addition of alkali to the sucrose experiment resulted in a reduced conversion of carbon to gas. In both experiments, the amount of methane was reduced. As shown in Figure 10, the activity of the catalytic system is lost over time whether or not sodium carbonate is added.

The aqueous effluent product from the sorghum experiments was used as feedstock in a further experiment to determine if the organic chemical intermediates would have the same catalyst deactivation effect as seen with the whole biomass. The loss in activity of the catalyst can be seen in Figure 9. The rate of loss of catalyst activity as a function of feedstock processed is similar to that of the sorghum itself, although the carbon conversion is slightly higher.

\section{ADDITIONAL RESEARCH}

The results from the CRS tests suggest that efficient conversion of high-moisture biomass to useful gaseous fuel can be attained in a highpressure, thermocatalytic reactor system. Unfortunately, this program of research was terminated before a full study of reaction parameters could be made in order to fully optimize the process. Furthermore, planned research with alternative catalysts, which were believed to have improved operating lifetimes, was not completed.

Additional tests are needed to define the relationship of temperature and pressure in the reaction system. In the experiments already completed in the CRS, pressure has not been evaluated as an independent variable. The full range of the reactor operation (1500 to $6000 \mathrm{psig}$ ) has not been tested. Experimental evaluation of the full range of operating parameters will provide a better understanding of the reaction system and may identify important operating differences.

A more complete study of nickel catalyst types needs to be completed to identify the best catalyst composition for the process. Only two catalysts have been tested in these experiments, whereas a wide range of nickel concentrations and support compositions are commercially available. Further 


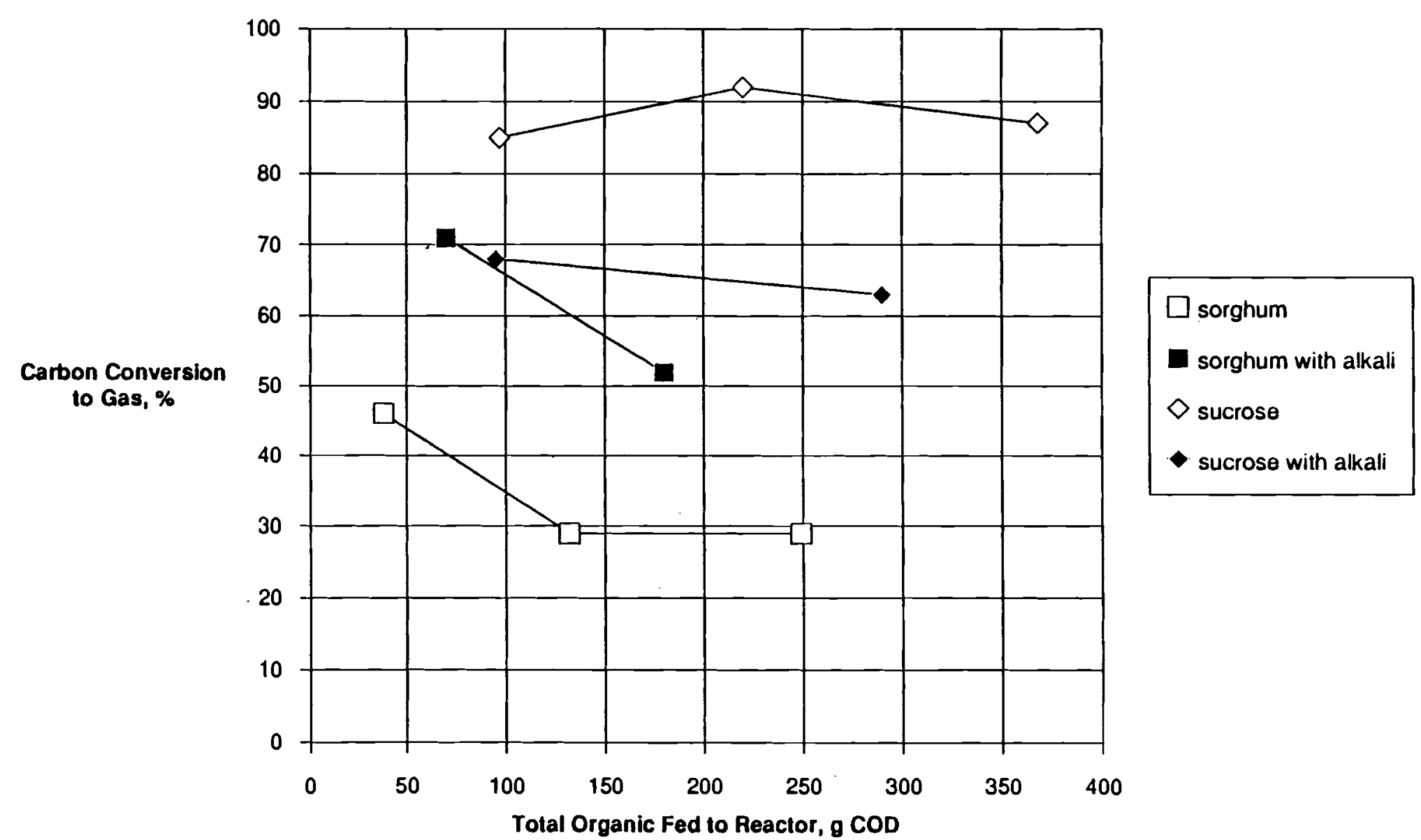

FIGURE 10. Conversion with Added Sodium Carbonate as a Function of the Amount of Feedstock Processed 
experiments are also required to fully understand the mechanism of catalyst deactivation. By processing feedstocks containing varying amounts of inorganic components and supported by an expanded program of analysis of the feedstocks and spent catalysts, we expect to define the deactivation mechanism. Through further process development, an appropriate catalytic reactor system can be engineered to handle the process without degradation of the catalyst bed. 
TECHNOLOGY TRANSEER AND PROCESS DEVELOPMENT.

\section{TECHNOLOGY TRANSFER}

Pacific Northwest Laboratory manages an aggressive technology transfer program to help U.S. industries implement the results of federally developed technologies. As part of this program, the results of high-moisture biomass gasification research and other spinoff applications of the technology are being transferred to industry to assist in solving technical problems and to help meet future energy and environmental needs.

Pacific Northwest Laboratory's technology transfer program is effective through a broad range of mechanisms, including:

- the ability to tailor general results from federally supported research and development programs to suit specific needs and products of industry

- the ability to enter into license agreements with industry

- the ability to develop research and development consortia for industry

- the ability to identify and develop new, innovative methods for transferring technol ogy.

All of the above mechanisms are being used to transfer the PNL-developed, high-moisture biomass gasification technology to industry. In addition, other commonly used technology transfer approaches (incl uding technology awareness and industrial exchange programs, publications and technology transfer bulletins, responses to inquiries, creation of spinoff companies, and cooperative research programs) are being used or are being contemplated.

\section{Patent Status and Licensing Aqreement}

A patent is pending on the high-moisture biomass gasification process that was developed under a basic research project (Sealock, Elliott, and Hallen 1982) sponsored by the Gas Research Institute (GRI). Battelle Development Corporation (BDC) has purchased from GRI all of GRI's right, title, and interest in the invention and patent. 
Through PNL, BDC has subsequently entered a .licensing agreement with Onsite*0fsite, Inc., located in Pasadena, Cal ifornia. Onsite*ofsite, a turnkey design engineering and construction management firm, has been granted the exclusive rights to license the process for the gasification of biomass and several other types of waste materials, including solid waste, food processing wastes, industrially generated organic and hazardous waste, and the waste waters associated with the use and processing of these feedstocks. Onsite*0fsite is aiding PNL in transferring the high-moisture biomass and related technology to industry and is currently discussing sublicensing the technol ogy to various firms.

Several additional continuation-in-part patent applications were filed during the first half of 1988 to establish ownership of the technology in the biomass, food processing, water cleanup, and hazardous waste destruction fields. These patent applications are still being prosecuted. Onsite*0fsite is actively marketing the technology in the fields listed above, and industrial support and involvement for the development of various applications of the technology is progressing. This notable industrial interest increases the potential for cost sharing of larger-scale systems. Several major companies have expressed interest in the technology (mainly as an energy production/waste disposal technology and as a water treatment system).

\section{Commercialization}

The thermocatalytic, high-moisture gasification system investigated in this project is being commercialized and transferred to industry as the Thermochemical Environmental Energy System (TEES). The TEES name applies to the production of energy from biomass and other concentrated sources of organic feedstocks such as solid wastes and food processing waste. This system was recognized with an R\&D 100 award in 1989 as one of the top 100 new technical developments to reach the marketplace during 1988. Associated technology for the treatment of hazardous waste and organic-containing waste waters is also being commercialized as the Catalytic Organic Aqueous Treatment System (COATS). The latter technology was developed by funds provided by the PNL Northwest Hazardous Waste Research, Development, and Demonstration Center (sponsored by DOE). Batch reactor tests and initial 
tests in the high-moisture biomass CRS with hazardous organics have been completed. Positive experimental results were obtained in the proof-ofprinciple tests conducted in the batch reactor in FY 1987 (Baker and Sealock 1988a,b). These tests led to the filing of a continuation-in-part patent application in 1988. Further investigation in the CRS has shown even more promising results (Baker et al. 1989b).

As part of their commercialization effort, Onsite*0fsite has (at their own expense) prepared prel iminary designs and models for a 5-wet-ton/day transportable unit and for a 1-wet-ton/day skid-mounted process development unit (PDU) for potential location at the PNL Chemical Engineering Laboratory. A model of the mobile unit designed for gasification of food processing and other waste materials including hazardous organic waste is shown in Figure 11. They have also prepared preliminary cost estimates for several commercial applications and for the two process development units.

Federal Laboratorv Consorti um Award

Due to the emphasis and effort devoted to technology transfer by PNL and Onsite*Ofsite, L. J. Sealock, Jr., E. G. Baker, D. C. Elliott, and R. S. Butner of PNL received a Federal Laboratory Consortium (FLC) Award for Excel lence in Technology Transfer for TEES. The award was in recognition of an innovative alliance between a small business (Onsite*0fsite) and the Laboratory to commercialize and transfer to industry a novel waste management and energy production system.

The FLC award acknowledges efforts by government agencies, their personnel, and contractors for transferring products and processes to private industry. The FLC, which promotes and coordinates technology transfer for more than 400 federal laboratories and research centers from 14 federal agencies, annually presents up to 30 Excellence in Technology Transfer Awards. Pacific Northwest Laboratory has won 11 such awards since the program was established in 1984. 


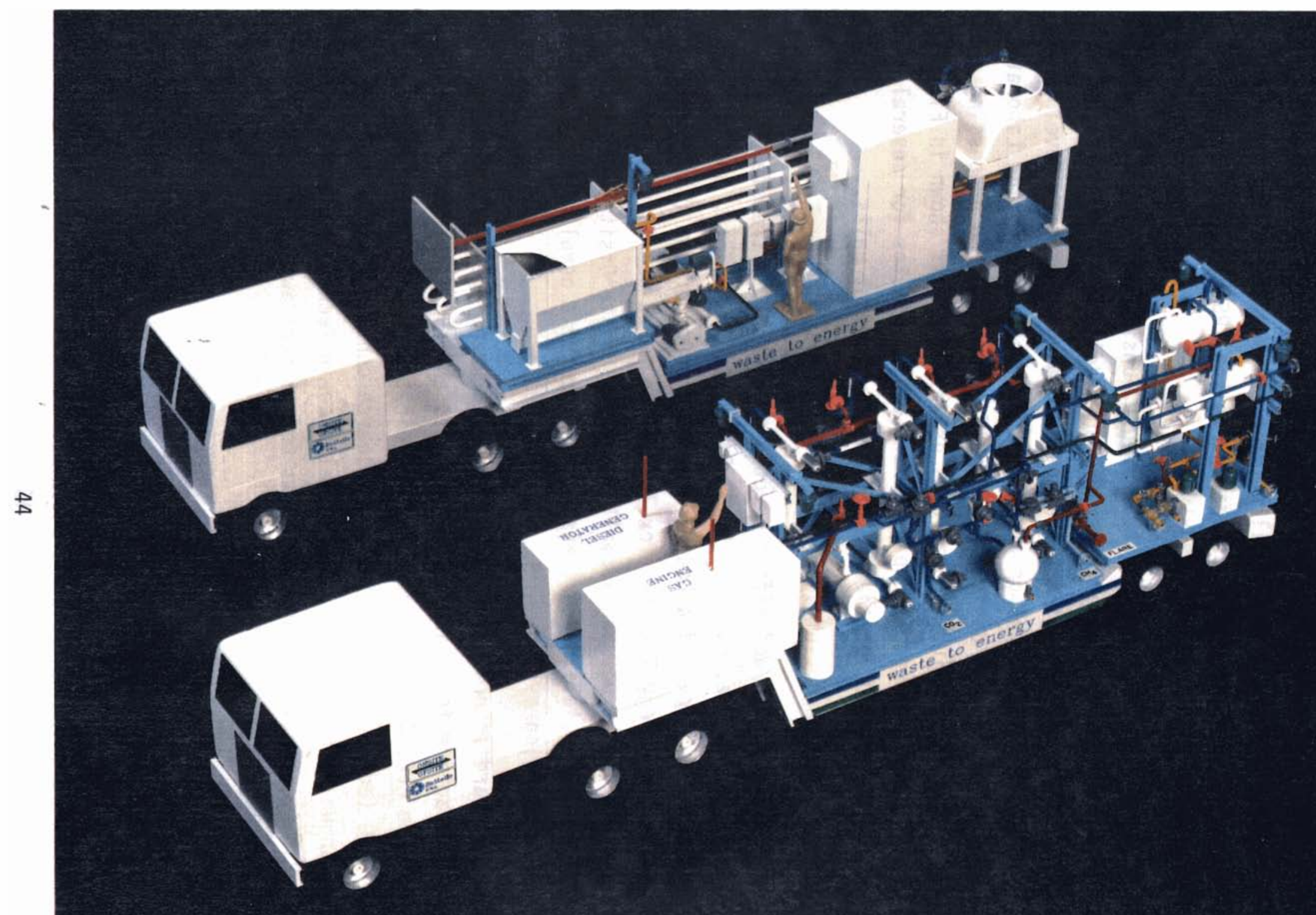

FIGURE 11. Model of Mobile Pilot Facility 


\section{PROCESS DEVELOPMENT}

The CRS, built in 1988, was designed to obtain basic engineering data (including isothermal rate data) needed to fully evaluate the commercial and technical potential of the high-moisture gasification concept. The CRS was built to evaluate alternative catalysts, develop catalyst deactivation and lifetime data, determine kinetic parameters for the conversion of a variety of feedstocks, and to fully define and analyze the concept and evaluate its integration into specific applications. This information is required before the process can be advanced to a larger scale.

With the results obtained with the CRS so far, engineering-scale research is now possible. Kinetic information has been developed that can be used for designing a plug-flow tubular reactor. Additional engineeringscale studies should be undertaken before the system is upgraded to largescale commercial applications.

\section{Tubular Reactor Studies}

As described earlier in this report, the reactor used in the CRS studies was a Carberry spinning basket reactor. The reactor is gradientless (isothermal and uniform composition throughout) and is physically equivalent to a continuous stirred-tank reactor (CSTR). The high-speed rotation of the catalyst basket minimizes bulk-phase and interparticle mass and heat transfer effects. These factors make the reactor ideal for obtaining true reaction rate data. Kinetic parameters obtained with this reactor can be used to design other types of reactors, such as fixed-bed tubular reactors. However, because of the high degree of back-mixing, the CSTR is not designed for obtaining high conversions. A fixed-bed tubular reactor is generally the best choice for obtaining high conversions and is mechanically simpler and, as a result, less expensive to build. The scaleup design is based on this type of reactor.

A small-scale tubular reactor has been ordered that can be integrated into the CRS in place of the CSTR. The CRS could then be used with the tubular reactor to confirm the kinetic data obtained with the CSTR and to "model" the larger-scale PDU and other scaleup designs developed by 
Onsite*0fsite. This activity would help to confirm scaleup information and lower the risk involved when larger systems are built.

Two important concerns were addressed in selecting and designing the tubular reactor for integration into the CRS. The first was to ensure that plug flow or near plug flow was obtained in the reactor, and the second was to ensure that mass transfer did not limit the overall rate of conversion. For application here, the flow of liquids or dense fluids through a packed bed of catalyst particles should approach plug flow. The ratio of the length of the reactor to the diameter of the particle should exceed 120 to ensure that plug flow is achieved.

Resistance due to mass transfer could occur in a fixed-bed, tubular reactor because of pore diffusion or transfer from the catalyst surface to the bulk of the fluid. The Thiele Modulus was calculated, which indicated that pore diffusion should not be a problem. It also appears that limitations due to mass transfer from the solid catalyst to the bulk of the fluid can be avoided. $\mathrm{K}_{\mathrm{g}} \mathrm{a}$, which is the mass transfer coefficient times the external surface area of the catalyst, was also calculated and compared with the first-order rate constant for the reaction. When $\mathrm{K}_{\mathrm{g}} \mathrm{a}$ is much larger than the apparent rate constant, mass transfer from the solid to the fluid should not be a significant factor. By using 1/4-in. rashig rings for PDU and scaleup applications, a $\mathbf{K}_{\mathrm{g}} \mathrm{a}$ up to an order of magnitude larger than the rate constant is obtained, which should eliminate most mass transfer effects.

Operation of a small-scale tubular reactor will verify these calculations and previously obtained kinetic information. A commercially available tubular reactor manufactured by High Pressure Equipment was selected for use in the CRS. The reactor is a 2 -in. O.D. by 1 -in. I.D. reactor, $6 \mathrm{ft}$ long. Table 10 shows some of the key design factors for this reactor and for the proposed tubular reactor in the PDU. The only factor that varies significantly is the catalyst bed length to particle diameter ratio, which is much greater in the CRS. However, the ratio for both reactors is much greater than the 120 required for plug flow. The data obtained from this reactor are expected to accurately model how the PDU and other potential scaleup reactors are going to perform. 
TABLE.10. Design Factors for CRS and PDU Tubular Reactors

Bench-Scale CRS

Flow Rate, L/h (feed $025^{\circ} \mathrm{C}, 1 \mathrm{~atm}$ )

Reactor Diameter, in I.D.

Reactor Length, ft

Bed Depth, ft

Catalyst Diameter, in.

Reactor Volume, L

Residence Time, min

Superficial Linear Velocity, $\mathrm{cm} / \mathrm{s}$

Reynolds Number

Mass Transfer Factor, $\mathrm{K}_{\mathrm{g}} \mathrm{a}, \mathrm{s}^{-1}$

1 st Order Rate Constant, $\mathrm{s}^{-1}$

Reactor Internal Ratio, Length to Diameter

Catalyst Ratio, Bed Length to

Particle Diameter
1.0

0.75

6.0

5.0

$1 / 16$ extrudates

0.43

9.6

0.18

0.53

0.53

0.015

96

960
Process

Development Unit

38

4.0

8.0

7.0

$1 / 4$ rashig rings

17.3

10.1

0.24

2.85

0.058

0.015

\section{Evaluation of Process Economics}

Process economics has not been an area of detailed analysis in this project because of the limited number of CRS experiments. Numerous batch experiments have been completed (Elliott and Sealock 1985; Sealock et al. 1988), but these experiments were at a small scale of development and were not operated in a manner that facilitates economics estimates. Furthermore, since the process is in an early stage of development, it is continually being developed and improved and is therefore subject to changes. A preliminary analysis was undertaken previously for GRI (Pack, Desrosiers, and Kamali 1985). Large contingencies were required because of uncertainties related to process kinetics, reactor design, catalyst lifetime, and biomass feeding systems. A detailed economic analysis is planned in conjunction with future proposed work. The economic analysis would occur following additional operation of the CRS and would incorporate more definitive information on feeding systems, catalyst lifetime, and process kinetics. 
Preliminary process economics by Onsite*0fsite for the TEES concept have recently been developed for general applications based on batch and CRS experiments. The product gas is primarily methane and carbon dioxide and should be compatible with existing natural gas burners without modification of the gas nozzles. The gas can be delivered at greater than $1500 \mathrm{psig}$, and in a commercial-scale process could be expanded through a power recovery turbine to further enhance energy recovery. The product gas is essentially free of nitrogen and can be processed using a number of commercially avail able technologies to obtain a pipeline-quality gas. The gas could also be burned in a diesel or spark-ignition engine to produce shaft power or electricity.

When high conversion is achieved, the effluent from the process can be discharged directly to a publicly owned treatment works or an existing onsite treatment plant. Depending on local standards and the feedstock used, it may be possible to discharge the effluent directly to a surface water stream. The significant reduction in COD in the effluent stream compared with the feed material should be of great economic benefit to processing operations that are charged for water treatment on the basis of discharge quality, or for those operations operating at or above the capacity of their treatment facilities.

Based on the encouraging experimental results from both the batch reactor studies and the CRS studies, PNL is working with Onsite*0fsite to obtain funds to build a 1-wet-ton/day PDU to demonstrate the process on a commercial scale. The facility would be skid-mounted so it could be transferred to a number of food processing facilities for testing with several different wastes. Onsite*0fsite has prepared a detailed process flow diagram (Figure 12). The process uses a recycled water stream for feedstocks where water must be added to facilitate slurry preparation and pumping. The product gas can be treated and used in a number of different ways depending on the plant requirements. The flow diagram in Figure 12 includes a membrane separation of the gas, which would be employed where the user required a high-Btu content gas ( $>900 \mathrm{Btu} / \mathrm{scf}$ ) or desired a relatively pure carbon dioxide byproduct stream (e.g., for controlled-atmosphere storage or carbonation). Other end configurations can be developed for different needs. 


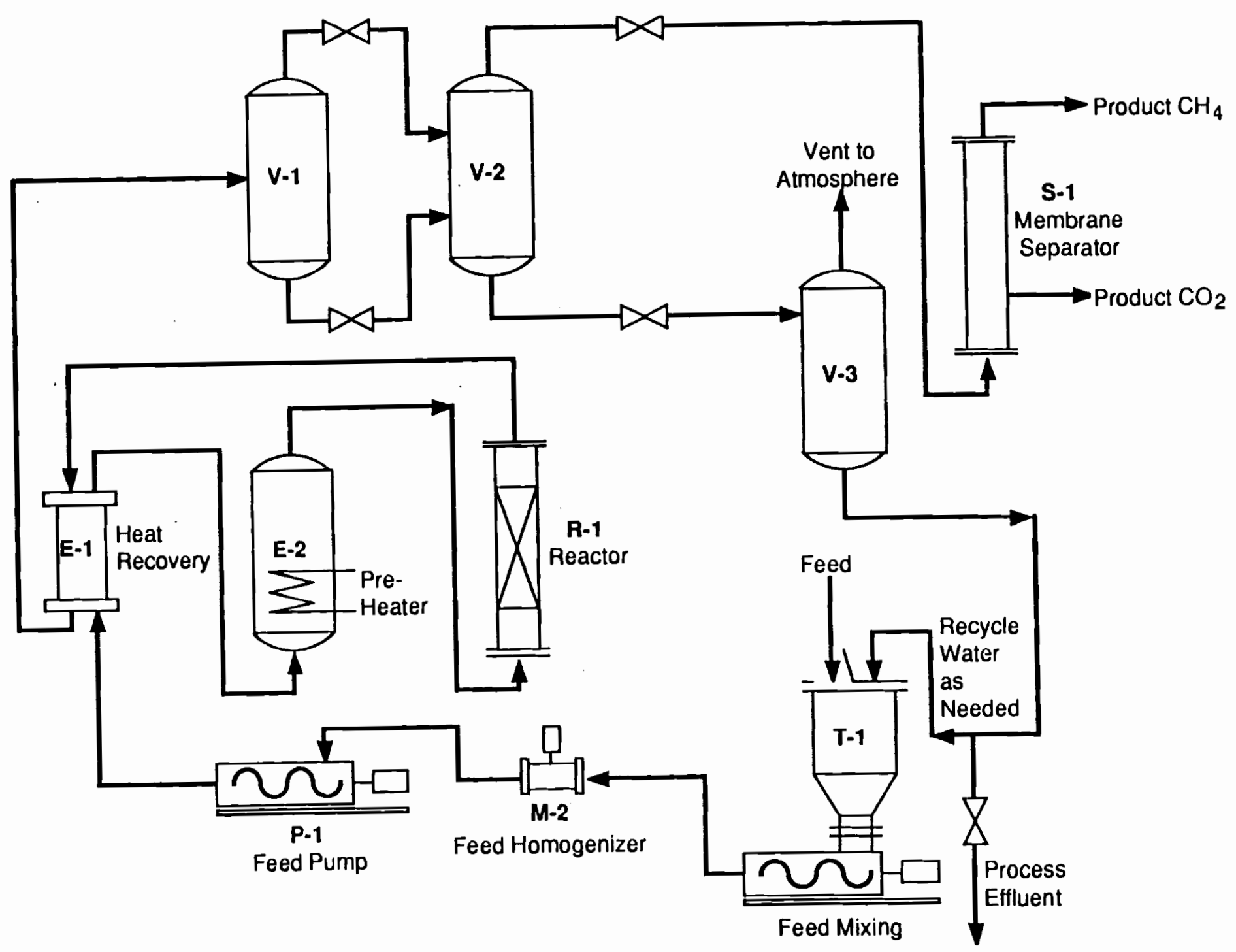

FIGURE 12. Conceptual Flow Diagram of the Thermocatalytic Conversion Process 
Onsite*Ofsite has also estimated (for a private client) the cost of a 150-gpm plant (approximately 850 tons per day of waste containing $9.2 \%$ sol ids) to handle food processing wastes. The estimated capital cost, based on a 10 -min reactor residence time, is $\$ 10.2$ million. A $12 \%$ discounted cash flow rate of return on investment would show the cost of the gas produced to be $\$ 6.20$ per million Btu assuming no credit for waste disposal savings. However, if it costs $\$ 3$ per ton to dispose of the waste, the net cost of the gas produced falls to about $\$ 3$ per million Btu.

The economics of the TEES process is expected to improve as additional process information is developed and as improvements are incorporated and uncertainties removed. Current economics are very site specific and are dependent primarily on the costs for waste disposal and the incremental cost of energy at individual facilities. The waste disposal cost and the cost of energy for several potential applications of the TEES process are shown in Table 11. The cost of fuel used at these facilities ranges from $\$ 2.40$ to $\$ 5.00$ per million Btu. Waste disposal costs have an even wider range from $\$ 26.60$ per ton for cranberry presscake to -513.80 per ton for spent grain currently sold as cattle feed.

For several companies, the TEES process would be economical today, e.g., for disposing of cranberry presscake in the Northwest where both natural gas costs and waste disposal costs are high. Other companies are quite interested in the process for future use because they anticipate a significant increase in their waste disposal and energy costs. Several examples of potential applications are 1 isted below:

- Pineapple silage water is being disposed of by deep well injection, which is expected to be halted in the near future.

- Spent coffee grounds can no longer be "land treated" and are accumulating at a plant.site until another disposal method is identified.

- Effluent water from spent grain dewatering is being disposed of in a publicly owned treatment works, and the cost is escalating rapidly. 
TABLE 11. Comparison of Current Fuel Costs and Waste Disposal Costs for Selected Industries

\begin{tabular}{|c|c|c|c|c|}
\hline Location & Fuel' Type & $\begin{array}{l}\text { Fuel Cost, } \\
\$ / M M B t u\end{array}$ & Waste Type & $\begin{array}{c}\text { Waste Disposal } \\
\text { Costs }(a) \\
\$ / \text { wet ton } \\
\end{array}$ \\
\hline Midwest & Coal & -- & Brewer's Spent Grain & $-13.3(b)$ \\
\hline California & $\begin{array}{l}\text { Natural Gas } \\
\text { No. } 6 \text { Fuel } \\
0 \text { i1 }\end{array}$ & $\begin{array}{l}5.00 \\
3.22\end{array}$ & Brewer's Spent Grain & $-13.8(b)$ \\
\hline Northwest & Bunker 0 i1 & 4.90 & Cranberry Presscake & 26.6 \\
\hline Northwest & Natural Gas & 4.80 & Fruit Pomace & 3.3 \\
\hline California & $\begin{array}{l}\text { No. } 6 \text { fuel } \\
\text { oi } 1\end{array}$ & 2.45 & Spent Coffee Grounds & 7.1 \\
\hline Southwest & Natural Gas & 3.75 & $\begin{array}{l}\text { Cattle Feedlot } \\
\text { Manure }\end{array}$ & 1.5 \\
\hline California & Natural Gas & 2.40 & Grape Pomace & -38.0 \\
\hline Hawai i & $\begin{array}{l}\text { No. } 6 \text { Fuel } \\
0 \text { i } 1\end{array}$ & 2.45 & $\begin{array}{l}\text { Pineapple Silage } \\
\text { Water }\end{array}$ & $0(c)$ \\
\hline California & Natural Gas & 2.80 & Cheese Whey & 0.6 \\
\hline Northwest & Natural Gas & 2.75 & Cheese Whey & 1.8 \\
\hline Midwest & $\begin{array}{l}\text { Natural Gas } \\
\text { No. } 2 \text { Fuel } \\
\text { Oi1 } \\
\text { Coal }\end{array}$ & $\begin{array}{c}2.80-4.77 \\
3.36 \\
1.70\end{array}$ & $\begin{array}{l}\text { Water Treatment } \\
\text { Sludge }\end{array}$ & 2.5 \\
\hline
\end{tabular}

(a) Negative number indicates that waste is currently being sold.

(b) Does not include cost of dewatering and drying the feed, and the associated waste water treatment costs.

(c) 4 1/2 million gallons per day of silage water are currently being disposed of by deep well injection. Well injection is expected to be stopped in the near future. 
- Cheese whey is being "land treated," which is likely to become more expensive or stopped completely.

- Grape pomace cannot always be sold and is accumulating at some plant sites.

\section{Future Work}

Additional research in the food processing area is proposed for funding in late FY 1989 to the DOE Waste Energy Reduction Division of the Office of Industrial Programs. Work in the catalytic destruction research area is proposed to DOE-Defense Programs. Funding for bench-scale continuous reactor tests is expected in FY 1990. Industry-funded research in this area is also anticipated. Continued effort will be expended in obtaining joint government and private funds to build a scaleup unit that can be used to provide the technical and economic information required for a commercial system. 


\section{RELATED PUBLICATIONS}

This document is the second formal report for the DOE-funded project,

"Low-Temperature Thermochemical Conversion of High-Moisture Biomass Feedstocks to High-Valued Fuels." An ongoing record of monthly and quarterly technical progress reports has been submitted to the Technical Field Office for Biomass Thermochemical Conversion and to the Program Manager for Thermochemical Conversion in the Biofuels and Municipal Waste Technology Division at DOE Headquarters in Washington, D.C. In addition, papers have been submitted to the periodic Proceedings of the Biomass Thermochemical Conversion Contractors' Meeting. Numerous other journal articles, symposium proceedings, papers, and presentations have been prepared as part of this project. These documents are listed in the first topical report (Sealock et al. 1988), which described the batch reactor tests performed in preparation for the CRS tests described here. Since these documents relate to the batch reactor tests they are not listed again here. This report is the only formal publication of the CRS tests with high-moisture biomass (cellulose and sorghum slurries). 



\section{REFERENCES}

Baker, E. G., and L. J. Sealock, Jr. 1988a. "Catalytic Destruction of Hazardous Organics in Aqueous Wastes." In Proceedinss of the 5 th National Conference on Hazardous Wastes and Materials, April 19-21, Las Vegas, Nevada.

Baker, E. G., and L. J. Sealock, Jr. 1988b. Catalytic Destruction of Hazardous Oraanics in Aqueous Solutions. PNL-6491-2, Pacific Northwest Laboratory, Richland, Washington.

Baker, E. G., R. S. Butner, L. J. Sealock, Jr., D. C. Elliott, and G. G. Neuenschwander. 1989a. Thermocatalvtic Conversion of Food Processing Wastes: Topical Report FY 1988. PNL-6784, Pacific Northwest Laboratory, Richland, Washington.

Baker, E. G., R. S. Butner, L. J. Sealock, Jr., D. C. Elliott, G. G. Neuenschwander, and N. G. Banns. 1989b. "Catalytic Destruction of Hazardous Organics in Aqueous Wastes: Continuous Reactor System Experiments." Hazardous Waste \& Hazardous Materials 6(1):87-94.

Elliott, D. C., and L. J. Sealock, Jr. 1985. "Low Temperature Gasification of Biomass Under Pressure." In Fundamentals of Thermochemical Biomass Conversion, eds. R. P. Overend, T. A. Milne, and L. K. Mudge, pp. 937-950. Elsevier Applied Science Publishers, Ltd., London.

Elliott, D. C., L. J. Sealock, Jr., and R. S. Butner. 1988. "Product Analysis from Direct Liquefaction of Several High-Moisture Biomass Feedstocks." In Pyrolysis 0ils from Biomass: Producing. Analvzing. and Uparading, ACS Symposium Series \#376, eds. E. J. Soltes and T. A. Milne, pp. 179-188. American Chemical Society, Washington, D.C.

Nelson, D. A., R. T. Hallen, and 0. Theander. 1988. "Formation of Aromatic Compounds from Carbohydrates: Reaction of Xylose, Glucose, and Glucouronic Acid in Acidic Solution at $300^{\circ} \mathrm{C} . "$ In Pyrolysis Oils from Biomass: Producina. Analyzina, and Uparadina, ACS Symposium Series \#376, eds. E. J. Soltes and T. A Milne, pp. 113-118. American Chemical Society, Washington, D.C.

Pack, G. E., R. E. Desrosiers, and K. Kamali. 1985. Preliminarv Technical and Economic Evaluation of a Low Temperature Thermochemical Gasification Process. GRI-85/0058, Gas Research Institute, Chicago.

Sealock, L. J., Jr., D. C. Elliott, R. S. Butner, and G. G. Neuenschwander. 1988. Low-Temperature Conversion of Hiah-Moisture Biomass: Topical Report January 1984 - January 1988. PNL-6726, Pacific Northwest Laboratory, Richland, Washington. 
Sealock, L. J., Jr., D. C. Elliott, and R. T. Hallen. 1982. "Kinetics and Catalysis of Producing Synthetic Gases from Biomass." Final Report. GRI82/0038, PB83-188644, National Technical Information Service, Springfield, Virginia. 
APPENDIX

OPERATING CONDITIONS FOR EXPERIMENTS 

Experiment Number (Date)

\begin{tabular}{|c|c|c|c|c|c|c|}
\hline Parameters & $\begin{array}{c}A \\
(--)\end{array}$ & $\begin{array}{l}B \\
(--)\end{array}$ & $\begin{array}{c}1 \\
14 / 13) \\
\end{array}$ & $\begin{array}{c}2 \\
(4 / 26)\end{array}$ & $\begin{array}{r}3(a) \\
(5 / 3) \\
\end{array}$ & $\begin{array}{l}3^{(b)} \\
(6 / 16) \\
\end{array}$ \\
\hline Catalyst & $\mathrm{Ni} 1404$ & $\mathrm{Ni1404}$ & $\mathrm{Ni} 1404$ & $\mathrm{Ni} 1404$ & Ni1404 & $\mathrm{Ni} 1404$ \\
\hline Catalyst Loading, g & -- & - & 158.82 & 161.00 & 153.69 & -- \\
\hline Temperature, ${ }^{\circ} \mathrm{C}$ & -380 & -380 & -380 & -380 & -350 & -350 \\
\hline Pressure, psig & -4000 & -4000 & -5000 & -4850 & -4000 & -4000 \\
\hline Feedstock & water & water & cellul & cellul & cellul & cellul \\
\hline Concentration, wt\% & 100 & 100 & 5.01 & 5.01 & -5 & -5 \\
\hline$\infty$ of Feedstock, $g / L$ & -- & -- & -- & -- & - & -- \\
\hline Feed Pump Setting & -- & -- & $50 \%$ & $30 \%$ & $\cdots$ & -- \\
\hline Feed Rate, $\mathrm{mL} / \mathrm{h}$ & -- & -- & 1104 & 532 & -- & -- \\
\hline Feed Rate, g COD/h & $\cdots$ & $\cdots$ & $\cdots$ & - & -- & - \\
\hline$\infty 00$ of Effluent, $g / L$ & -- & -- & $\cdots$ & -- & -- & -- \\
\hline$\infty$ Reduction, \% & -- & -- & -- & -- & - & -- \\
\hline $\begin{array}{l}\text { Carbon Conversion } \\
\text { to Gas, } \%\end{array}$ & -- & - & -- & -- & -- & -- \\
\hline Gas Yield, L/h & - & - & -- & $-\cdot$ & -- & -- \\
\hline $\begin{array}{l}\text { Gas Composition, vol\% } \\
\text { Hydrogen } \\
\text { Carbon Dioxide } \\
\text { Methane } \\
\text { Ethane } \\
\text { Carbon Monoxide } \\
\text { Backflush }\end{array}$ & $\begin{array}{l}-- \\
-- \\
-- \\
-- \\
-- \\
--\end{array}$ & $\begin{array}{l}-- \\
-- \\
-- \\
-- \\
-- \\
--\end{array}$ & $\begin{array}{l}2 \\
54 \\
31 \\
0.2 \\
2 \\
--\end{array}$ & $\begin{array}{l}-- \\
-- \\
-- \\
-- \\
--\end{array}$ & $\begin{array}{l}-- \\
-- \\
-- \\
-- \\
-- \\
--\end{array}$ & $\begin{array}{l}-- \\
-- \\
-- \\
-- \\
-- \\
--\end{array}$ \\
\hline $\begin{array}{l}\text { Gas Yield, L/g dry feed } \\
\text { HHV gas, Btu } / \mathrm{ft}^{3}\end{array}$ & $\begin{array}{l}-\cdot \\
-\end{array}$ & -- & $\cdots$ & $\cdots$ & $\cdots$ & $\cdots$ \\
\hline Carbon Catalyst, wt\% & -- & -- & -- & - & -- & -- \\
\hline Stream time, cumul min & $\cdots$ & - & 72 & 240 & 0 & 60 \\
\hline$\infty 0 D$ to Gas, g COD/h/L & -- & -- & $\cdots$ & -- & -- & -- \\
\hline cOD Reduction, g $\mathrm{COD} / \mathrm{h} / \mathrm{L}$ & $\cdots$ & -- & $\cdots$ & -- & -- & -- \\
\hline
\end{tabular}


Experiment Number (Date)

\begin{tabular}{|c|c|c|c|c|c|c|}
\hline Parameters & $\begin{array}{c}4 \\
(7 / 27) \\
\end{array}$ & $\begin{array}{c}5 \\
(10 / 7) \\
\end{array}$ & $\begin{array}{c}6 \\
(10 / 11) \\
\end{array}$ & $\begin{array}{c}7 \mathbf{i} \\
(10 / 18)\end{array}$ & $\begin{array}{c}7^{(a)} \\
(10 / 19) \\
\end{array}$ & $\begin{array}{c}7^{(b)} \\
(10 / 19) \\
\end{array}$ \\
\hline Catalyst & $\mathrm{Ni} 1404$ & $665 \mathrm{RS}$ & G65 R/S & G65 R/S & same & same \\
\hline Catalyst Loading, g & 160.52 & 146.59 & 140.29 & 140.41 & same & same \\
\hline Temperature, ${ }^{\circ} \mathrm{C}$ & $390-395$ & $401 \pm 3$ & $393 \pm 2$ & 374 & $399 \pm 1$ & $401 \pm 1$ \\
\hline Pressure, psig & $3850 \pm 250$ & 4060 & 3900 & 2870 & $3810 \pm 30$ & $3870 \pm 30$ \\
\hline Feedstock & cellut & sorghum & sorghum & sorghum & same & same \\
\hline Concentration, wt\% & $2-3$ & 6.6 & 5.1 & 4.7 & same & same \\
\hline$\infty O D$ of Feedstock, g/L & -- & 93.0 & 79.5 & 75.0 & same & same \\
\hline Feed Pump Setting & $30 \%$ & $40 \%$ & $46-38 \%$ & $40 \%$ & $30 \%$ & $30 \%$ \\
\hline Feed Rate, $\mathrm{mL} / \mathrm{h}$ & $-\cdot$ & 504 & 592 & $-0-$ & 500 & 511 \\
\hline Feed Rate, $g$ COD/h & - & 46.9 & 47.1 & -0 & 37.5 & 38.3 \\
\hline$\infty 00$ of Effluent, $g / L$ & - & 25.0 & 15.4 & -- & 15.2 & 35.0 \\
\hline$\infty 00$ Reduction, \% & - & 73 & 80 & - & 82 & 62 \\
\hline $\begin{array}{l}\text { Carbon Conversion } \\
\text { to Gas, \% }\end{array}$ & - & 53 & 42 & - & 46 & 29 \\
\hline Gas Yield, L/h & $\cdots$ & 16.2 & 15.0 & - & 13.0 & 9 \\
\hline $\begin{array}{l}\text { Gas Composition, vol\% } \\
\text { Hydrogen } \\
\text { Carbon Dioxide } \\
\text { Methane } \\
\text { Ethane } \\
\text { Carbon Monoxide } \\
\text { Backflush }\end{array}$ & $\begin{array}{l}-- \\
-- \\
-- \\
-- \\
--\end{array}$ & $\begin{array}{l}17 \\
46 \\
34 \\
0.7 \\
0.2 \\
2.0\end{array}$ & $\begin{array}{l}17 \\
47 \\
33 \\
0.8 \\
0.3 \\
2.0\end{array}$ & $\begin{array}{l}- \\
-- \\
-- \\
-- \\
--\end{array}$ & $\begin{array}{l}23 \\
46 \\
28 \\
0.8 \\
1.0 \\
0.7\end{array}$ & $\begin{array}{l}23 \\
58 \\
13 \\
0.6 \\
3.0 \\
2.4\end{array}$ \\
\hline Gas Yield, L/g dry feed & $-\cdot$ & 0.50 & 0.39 & $\cdots$ & 0.48 & 0.29 \\
\hline $\mathrm{HN}$ gas, Btu/ft ${ }^{3}$ & -- & 470 & 462 & - & 401 & 296 \\
\hline Carbon Catalyst, wt\% & $\cdots$ & 2.0 & 2.4 & - & -- & 4.3 \\
\hline Stream time, cumul min & 100 & 150 & 120 & 0 & 100 & 400 \\
\hline $\mathrm{COD}$ to Gas, g COD/h/L & -- & 125 & 119 & $\cdots$ & 93 & 59 \\
\hline$\infty 00$ Reduction, g COD/h/L & $\cdots$ & 229 & 252 & - & 205 & 158 \\
\hline
\end{tabular}


Experiment Number (Date)

\begin{tabular}{|c|c|c|c|c|c|c|}
\hline Parameters & $\begin{array}{r}8^{(a)} \\
(10 / 21) \\
\end{array}$ & $\begin{array}{c}8^{(b)} \\
(10 / 21) \\
\end{array}$ & $\begin{array}{c}9 \\
(10 / 25) \\
\end{array}$ & $\begin{array}{l}10^{(a)} \\
(10 / 27) \\
\end{array}$ & $\begin{array}{l}10^{(b)} \\
(10 / 27) \\
\end{array}$ & $\begin{array}{r}11 \\
(11 / 2) \\
\end{array}$ \\
\hline Catalyst & G65 R/S & same & G65 RS & G65 RS & same & G65 RS \\
\hline Catalyst Loading, g & 143.46 & same & 141.58 & 143.35 & same & -70 \\
\hline Temperature, ${ }^{\circ} \mathrm{C}$ & 400 & 400 & $401 \pm 3$ & $399 \pm 1$ & $398 \pm 1$ & $400 \pm 1$ \\
\hline Pressure, psig & $4150 \pm 30$ & $4120 \pm 30$ & $4130 \pm 30$ & $4120 \pm 40$ & $4150 \pm 100$ & $4130 \pm 40$ \\
\hline Feedstock & sorghum & same & sorghum & sorghum & same & sorghum \\
\hline Concentration, wt\% & 5.6 & same & 2.6 & 5.6 & same & 5.8 \\
\hline$\infty 00$ of Feedstock, $g / L$ & 89.0 & same & 40.5 & 89.0 & same & 83.0 \\
\hline Feed Pump Setting & $26 \%$ & $25 \%$ & $36 \%$ & $36 \%$ & $37 \%$ & $30 \%$ \\
\hline Feed Rate, $\mathrm{mL} / \mathrm{h}$ & 324 & 332 & 585 & 648 & 845 & 593 \\
\hline Feed Rate, g COD/h & 28.8 & 29.5 & 23.7 & 57.7 & 75.2 & 49.2 \\
\hline$\infty D$ of Effluent, $g / L$ & 20.0 & 32.0 & 14.4 & 38.1 & 36.1 & 35.7 \\
\hline COD Reduction, \% & 85 & 77 & 70 & 57 & 68 & 62 \\
\hline $\begin{array}{l}\text { Carbon Conversion } \\
\text { to Gas, \% }\end{array}$ & 56 & 40 & 81 & 34 & 25 & 27 \\
\hline Gas Yield, L/h & 11.2 & 8.0 & 14.4 & 12.6 & 11.5 & 8.6 \\
\hline $\begin{array}{l}\text { Gas Composition, vol\% } \\
\text { Hydrogen } \\
\text { Carbon Dioxide } \\
\text { Methane } \\
\text { Ethane } \\
\text { Carbon Monoxide } \\
\text { Backflush }\end{array}$ & $\begin{array}{l}18 \\
47 \\
32 \\
0.8 \\
1.7 \\
1.7\end{array}$ & $\begin{array}{l}19 \\
54 \\
21 \\
0.8 \\
2.3 \\
3.1\end{array}$ & $\begin{array}{l}26 \\
41 \\
31 \\
0.6 \\
1.0 \\
1.0\end{array}$ & $\begin{array}{l}20 \\
53 \\
20 \\
0.6 \\
3.0 \\
2.9\end{array}$ & $\begin{array}{l}18 \\
62 \\
11 \\
1.0 \\
4.5 \\
3.5\end{array}$ & $\begin{array}{l}14 \\
62 \\
14 \\
1.0 \\
4.9 \\
4.1\end{array}$ \\
\hline Gas Yield, L/g dry feed & 0.54 & 0.37 & 0.88 & 0.32 & 0.23 & 0.23 \\
\hline $\mathrm{HHV}$ gas, $\mathrm{Btu} / \mathrm{ft}^{3}$ & 447 & 386 & 441 & 379 & 305 & 345 \\
\hline Carbon Catalyst, wt\% & -- & 3.8 & 2.1 & $-\cdot$ & 2.8 & 2.8 \\
\hline Stream time, cumul min & 165 & 405 & 255 & 90 & 350 & 220 \\
\hline$C O D$ to Gas, g $\operatorname{coD} / \mathrm{h} / \mathrm{L}$ & 108 & 79 & 128 & 131 & 125 & 89 \\
\hline $\cos$ Reduction, g $\operatorname{coD} / \mathrm{h} / \mathrm{L}$ & 163 & 152 & 110 & 219 & 341 & 204 \\
\hline
\end{tabular}


Experiment Number (Date)

\begin{tabular}{|c|c|c|c|c|c|c|}
\hline \multirow[b]{2}{*}{ Parameters } & \\
\hline & $\begin{array}{c}12 \\
(11 / 4) \\
\end{array}$ & $(113 / 8)$ & $\begin{array}{l}133^{(b)} \\
(11 / 8)\end{array}$ & $(11 / 10)$ & $(11)^{(b)}$ & $\begin{array}{r}15^{(a)} \\
(11 / 16) \\
\end{array}$ \\
\hline Catalyst & none & G65 RS & same & $665 \mathrm{R} / \mathrm{S}$ & same & $665 \mathrm{R} / \mathrm{S}$ \\
\hline Catalyst Loading, g & 0.0 & 139.55 & same & 136.68 & same & 141.50 \\
\hline Temperature, ${ }^{\bullet} \mathrm{C}$ & $398 \pm 1$ & $400 \pm 1$ & $400 \pm 1$ & $401 \pm 3$ & $401 \pm 3$ & $400 \pm 1$ \\
\hline Pressure, psig & 4060 & $4090 \pm 30$ & 4060 & 4030 & 4030 & 4070 \\
\hline Feedstock & sorghum & recycle & same & sorghum (a) & same $(a)$ & sorghum (a) \\
\hline Concentration, wt\% & 5.8 & -- & -. & 5.6 & same & -5 \\
\hline$\infty 00$ of Feedstock, $g / L$ & 82.0 & 27.6 & same & -. & -- & 72.0 \\
\hline Feed Pump Setting & $30 \%$ & $30 \%$ & $30 \%$ & $30-40 \%$ & $30 \%$ & $30 \%$ \\
\hline Feed Rate, $\mathrm{mL} / \mathrm{h}$ & 572 & 498 & 466 & unsteady & 500 & 506 \\
\hline Feed Rate, $g \mathrm{coD} / \mathrm{h}$ & 46.9 & 13.7 & 12.9 & $\cdots$ & $\cdots$ & 36.4 \\
\hline$\infty 00$ of Effluent, $g / L$ & 35.0 & 4.55 & 7.75 & -- & - & 20.0 \\
\hline$\infty$ Reduction, \% & 63 & 85 & 74 & - & - & 73 \\
\hline $\begin{array}{l}\text { Carbon Conversion } \\
\text { to Gas, } \%\end{array}$ & 22 & 82 & 68 & -- & - & 71 \\
\hline Gas Yield, L/h & 6.2 & 9.0 & 7.5 & - & -- & 20.4 \\
\hline $\begin{array}{l}\text { Gas Composition, vol\% } \\
\text { Hydrogen } \\
\text { Carbon Dioxide } \\
\text { Methane } \\
\text { Ethane } \\
\text { Carbon Monoxide } \\
\text { Backflush }\end{array}$ & $\begin{array}{l}10 \\
69 \\
10 \\
0.8 \\
5.4 \\
2.1\end{array}$ & $\begin{array}{l}32 \\
34 \\
34 \\
0.4 \\
0.0 \\
0.4\end{array}$ & $\begin{array}{l}37 \\
34 \\
27 \\
0.5 \\
0.0 \\
0.5\end{array}$ & $\begin{array}{l}- \\
- \\
-- \\
-- \\
-- \\
--\end{array}$ & $\begin{array}{l}-- \\
-- \\
-- \\
-- \\
--\end{array}$ & $\begin{array}{l}27 \\
44 \\
27 \\
1.1 \\
0.0 \\
1.2\end{array}$ \\
\hline Gas Yield, L/g dry feed & 0.17 & -- & -- & -- & - & 0.75 \\
\hline $\mathrm{HHV}$ gas, Btu/ $\mathrm{ft}^{3}$ & 314 & 461 & 422 & - & -- & 430 \\
\hline Carbon Catalyst, wt\% & - & - & 3.3 & -- & - & -- \\
\hline Stream time, cumul min & 205 & 305 & 465 & 240 & 195 & 150 \\
\hline$\infty 00$ to Gas, g COD/h/L & - & 65 & 51 & -- & - & 171 \\
\hline$\infty$ Reduction, g COD/h/L & - & 78 & 64 & -- & - & 177 \\
\hline
\end{tabular}


Experiment Number (Date)

\begin{tabular}{|c|c|c|c|c|c|c|}
\hline \multirow[b]{2}{*}{ Parameters } & \\
\hline & $\begin{array}{r}15^{(b)} \\
(11 / 16)\end{array}$ & $\begin{array}{r}06 a \\
(8 / 31) \\
\end{array}$ & $\begin{array}{c}06^{(b)} \\
(8 / 31) \\
\end{array}$ & $\begin{array}{c}06 c \\
(8 / 31)\end{array}$ & $\begin{array}{r}07(a) \\
(9 / 2) \\
\end{array}$ & $\begin{array}{l}07 \text { (b) } \\
(9 / 2) \\
\end{array}$ \\
\hline Catalyst & G65 RS & G65 R/S & same & same & G65 R/S & same \\
\hline Catalyst Loading, g & same & $150 \mathrm{cc}$ & same & same & 138.77 & same \\
\hline Temperature, ${ }^{\circ} \mathrm{C}$ & 399 & $398 \pm 5$ & $399 \pm 3$ & 39921 & 39822 & 40121 \\
\hline Pressure, psig & 4070 & $4200 \pm 30$ & $4220 \pm 10$ & $4070 \pm 30$ & 4200210 & $4200 \pm 30$ \\
\hline Feedstock & sorghum (a) & sucrose & same & same & sucrose $(b)$ & same $(b)$ \\
\hline Concentration, wt\% & -5 & 10 & same & same & 10 & same \\
\hline COD of Feedstock, $g / L$ & 72.0 & 116 & same & same & 115 & same \\
\hline Feed Pump Setting & $30 \%$ & $33-32 \%$ & $32-36 \%$ & $40 \%$ & $32 \%$ & $32 \%$ \\
\hline Feed Rate, $\mathrm{mL} / \mathrm{h}$ & 514 & 570 & 600 & 900 & 569 & 561 \\
\hline Feed Rate, g coD/h & 37.0 & 66.1 & 69.6 & 104.4 & 65.4 & 65.1 \\
\hline$\infty$ of Effluent, $g / L$ & 37.0 & 5.8 & 6.7 & 15.5 & 22.0 & 29.0 \\
\hline COD Reduction, \% & 56 & 95 & 94 & 88 & 83 & 77 \\
\hline $\begin{array}{l}\text { Carbon Conversion } \\
\text { to Gas, \% }\end{array}$ & 52 & 85 & 92 & 87 & 68 & 63 \\
\hline Gas Yield, L/h & 15.8 & 42.9 & 47.1 & 69.2 & 35.9 & 33.5 \\
\hline $\begin{array}{l}\text { Gas Composition, vol\% } \\
\text { Hydrogen } \\
\text { Carbon Dioxide } \\
\text { Methane } \\
\text { Ethane } \\
\text { Carbon Monoxide } \\
\text { Backflush }\end{array}$ & $\begin{array}{l}30 \\
46 \\
22 \\
0.7 \\
0.0 \\
1.3\end{array}$ & $\begin{array}{l}12 \\
46 \\
40 \\
0.5 \\
0.9 \\
0.2\end{array}$ & $\begin{array}{l}12 \\
48 \\
39 \\
0.6 \\
0.3 \\
0.2\end{array}$ & $\begin{array}{l}17 \\
45 \\
36 \\
1.0 \\
1.1 \\
0.7\end{array}$ & $\begin{array}{l}21 \\
46 \\
32 \\
0.5 \\
0.5 \\
0.6\end{array}$ & $\begin{array}{l}23 \\
49 \\
25 \\
1.0 \\
0.6 \\
1.0\end{array}$ \\
\hline Gas Yield, L/g dry feed & 0.57 & 0.75 & 0.78 & 0.77 & 0.63 & 0.60 \\
\hline $\mathrm{HHV}$ gas, Btu/ $\mathrm{ft}^{3}$ & 383 & 467 & 455 & 459 & 423 & 382 \\
\hline Carbon Catalyst, wt\% & 6.1 & - & - & -- & -- & - \\
\hline Stream time, cumul min & 350 & 120 & 240 & 310 & 105 & 265 \\
\hline COD to Gas, $g \mathrm{COD} / \mathrm{h} / \mathrm{L}$ & 127 & 375 & 427 & 606 & 297 & 273 \\
\hline COD Reduction, g COD/h/L & 139 & 418 & 438 & 611 & 362 & 336 \\
\hline
\end{tabular}

(a) Sodium carbonate, 2 wt\% of the slurry, added to the feedstock.

(b) Sodium carbonate and potassium carbonate, $1 \mathrm{wt} \%$ of the slurry each, added to the feedstock. 



\section{DISTRIBUTION}

No. of

CoDies

OFFSITE

S. Friedrich

Biofuels and Municipal Waste

Technology Division

U.S. Department of Energy

Forrestal Building (CE-341)

1000 Independence Avenue

Washington, D.C. 20585

S. L. Natof

Office of Industrial Programs

U.S. Department of Energy

Forrestal Building (CE-141)

1000 Independence Avenue

Washington, D.C. 20585

12 DOE/Office of Scientific and

Technical Information

M. J. Antal

Department of Mechanical

Engineering

University of Hawaii

2540 Dole Street

Honolulu, HI 96822

P. Badger

Southeast Regional Biomass Energy

Program

Tennessee Valley Authority

435 Chemical Building

Muscle Shoals, AL 35660

R. E. Bailey

Kraft Food

2211 Sanders Rd.

Northbrook, IL 60062

5 N. G. Banns

Onsite*0fsite, Inc.

2500 E. Foothills Blvd

Suite 201

Pasadena, CA 91107
No. of

Copies

S. P. Barone

Gas Research Institute

8600 West Bryn Mawr Avenue

Chicago, IL 60631

R. Beale

Vice President, Operations

Lamb-Weston

P.O. Box C 1900

Tri Cities, WA 99302

C. G. Coble

Texas A\&M University

College Station, TX 77840

D. P. Chynoweth

Agricultural Engineering Department

Frazier Rogers Hall

University of Florida

Gainesvil1e, FL 32611

H. W. Ewart

Tree Top, Inc.

Technical Center

111 S. Railroad Ave.

P.O. Box 248

Selah, WA 98942

P. Fox

Pacific NW \& Alaska Regional Biomass Energy Program

Bonneville Power Administration

905 11th Avenue N.E.

Portland, OR 97208

B. Goodman

Solar Energy Institute

1617 Cole Blvd.

Golden, CO 80401

H. Haines

Energy Division DNRC

32 South Ewing

Helena, MT 59601 
No. of

Copies

B. Haley

Miller Brewing Company

651 N. 39th Street

Milwaukee, WI 53233

\section{W. M. McKinney}

United Catalysts, Inc.

P.O. Box 32370

Louisvi11e, KY 40302

H. Meyer

Gas Research Institute

8600 W. Bryn Mawr Avenue

Chicago, IL 60631

C. R. Nelson

Gas Research Institute

8600 West Bryn Mawr Avenue

Chicago, IL 60631

M. A Paisley

Battelle-Columbus Division

505 King Avenue

Columbus, $\mathrm{OH} 43201$

0. H. Pattison, P.E.

Southwest Bio-Energy, Inc.

Star Route, Box 58

Clovis, M 88101

J. Pereira

Process Development and Optimization Center

Corporate Research and Devel opment

Anheuser-Busch Companies, Inc

Executive Offices

One Busch Place

St. Louis, MO 63118

R. Radford

Ocean Spray Cranberries, Inc.

Box 195

Markham Star Route

Aberdeen, WA 98520
No. of

$\underline{\text { Copies }}$

G. Simons

California Energy Commission

1516 - 9th Street, MS-43

Sacramento, CA 95801

W. H. Smith

Center for Biomass Energy Systems

University of Florida

3038 McCarty Hall

Gainesville, FL 32611

F. Sparber

Independent Solar Research

Route 1, Box 192-A

Belin, NM 87002

D. J. Stevens

Solar Energy Research Institute

1617 Cole Blvd.

Golden, CO 80401

R. J. Weisskirchen

The Blitz-Weinhard Brewing Company

1133 West Burnside Street

Portland, OR 97209

\section{FOREIGN}

G. Pietsch

Salzgitter $A G$

Kurfurstendamm 32

Postfach 1506 27, D-1000

Berlin, F.R.G

Christian Roy

Université Laval

Chemical Engineering Department

Faculté des sciences et génie

Pavillion Pouliot

Sainte-Foy, Québec G1K 7P4

Canada

Domenico San Filippo

Research Division

Snamprogetti

20097 S. Donato Milanese

Milan, Italy 
No. of

Copies

QNSITE

DOE Richland Operations Office

D. R. Segna

58 Pacific Northwest Laboratorv

E. G. Baker

R. S. Butner

D. C. Elliott (3)
No. of

$\underline{\text { Copies }}$

E. A. Eschbach

S. R. Gano

G. G. Neuenschwander

G. F. Schiefelbein

L. J. Sealock, Jr. (40)

J. L. Straalsund

B. R. Stults

L. D. Williams

Publishing Coordination

Technical Report Files (5) 
